\title{
Variations of Soybean Meal and Corn Mixed Substrates in Physicochemical Characteristics and Microbiota During Two-Stage Solid-State Fermentation
}

\section{OPEN ACCESS}

Edited by:

Rosane Freitas Schwan Universidade Federal de Lavras, Brazi

Reviewed by:

Zhongyang Ding,

Jiangnan University, China Brian Gibson,

Technical University of Berlin,

Germany

*Correspondence: Zeqing Lu

zqlu2012@zju.edu.cn Mingliang Jin

mljin@zju.edu.cn Yizhen Wang

yizhenwang321@zju.edu.cn

${ }^{\dagger}$ These authors have contributed equally to this work

Specialty section:

This article was submitted to

Food Microbiology,

a section of the journal

Frontiers in Microbiology

Received: 07 April 2021

Accepted: 14 June 2021

Published: 17 August 2021

Citation:

Su W, Jiang Z, Hao L, Li W, Gong T, Zhang Y, Du S, Wang C,

Lu Z, Jin M and Wang Y (2021) Variations of Soybean Meal and Corn Mixed Substrates in Physicochemical Characteristics and Microbiota During Two-Stage Solid-State Fermentation.

Front. Microbiol. 12:688839.

doi: 10.3389/fmicb.2021.688839

\section{Weifa Sut, Zipeng Jiang ${ }^{\dagger}$ Lihong Hao, Wentao Li, Tao Gong, Yu Zhang, Shuai Du, Cheng Wang, Zeqing Lu*, Mingliang Jin* and Yizhen Wang*}

National Engineering Laboratory of Biological Feed Safety and Pollution Prevention and Control, Key Laboratory of Molecular Nutrition, Ministry of Education, Key Laboratory of Animal Nutrition and Feed, Ministry of Agriculture, Key Laboratory of Animal Nutrition and Feed Science of Zhejiang Province, Institute of Feed Science, Zhejiang University, Hangzhou, China

Corn germ meal (CGM) and corn gluten feed (CGF) are the two main corn byproducts (CBs) obtained from corn starch extraction. Due to their high fiber content, low protein content, and severe imbalance of amino acid, CBs are unable to be fully utilized by animals. In this study, the effect of microorganism, proteases, temperature, solid-liquid ratio, and time on nutritional properties of $\mathrm{CB}$ mixture feed (CMF) was investigated with the single-factor method and the response surface method to improve the nutritional quality and utilization of CBs. Fermentation with Pichia kudriavzevii, Lactobacillus plantarum, and neutral protease notably improved the nutritional properties of CMF under the fermentation conditions of $37^{\circ} \mathrm{C}$, solid-liquid ratio $(1.2: 1 \mathrm{~g} / \mathrm{ml})$, and $72 \mathrm{~h}$. After two-stage solid-stage fermentation, the crude protein (CP) and trichloroacetic acid-soluble protein (TCA-SP) in fermented CMF (FCMF) were increased $(p<0.05)$ by $14.28 \%$ and $25.53 \%$, respectively. The in vitro digestibility of CP and total amino acids of FCMF were significantly improved to $78.53 \%$ and $74.94 \%$, respectively. In addition, fermentation degraded fiber and provided more organic acids in the CMF. Multiple physicochemical analyses combined with high-throughput sequencing were performed to reveal the dynamic changes that occur during a two-stage solid-state fermentation process. Generally, Ascomycota became the predominant members of the community of the first-stage of fermentation, and after $36 \mathrm{~h}$ of anaerobic fermentation, Paenibacillus spp., Pantoea spp., and Lactobacillales were predominant. All of these processes increased the bacterial abundance and lactic acid content $(\rho<0.00)$. Our results suggest that two-stage solid-state fermentation with Pichia kudriavzevii, Lactobacillus plantarum, and protease can efficiently improve protein quality and nutrient utilization of CMF.

Keywords: corn byproducts, two-stage solid-state fermentation, nutritional value, microbiota, in vitro digestibility

Abbreviations: SSF, solid-state fermentation; CGM, corn germ meal; CGF, corn gluten feed; CBs, corn byproducts; CMF, CBs mixture feed; FCMF, two-stage solid-state fermented CBs mixture feed; DM, dry matter; EE, ether extract; AA, amino acid; CP, crude protein; TCA-SP, trichloroacetic acid soluble protein; CF, crude fiber; ADF, acid detergent fiber; NDF, neutral detergent fiber; SDS-PAGE, sodium dodecyl sulfate-polyacrylamide gel electrophoresis. 


\section{INTRODUCTION}

The competition for food between humans and livestock has become a topic with great concern in the past few years. The shortage of feed resources led to a sharp rise in the prices of conventional feed ingredients, such as corn, soybean meal, fish meal, etc. In order to reduce feed costs, less-expensive, alternative agricultural and industrial byproducts are increasingly included in livestock diets (Li et al., 2018). Corn is one of the most important cash crops in the world. Global corn production exceeded one billion tons per year, and the cornprocessing industry produced large quantities of byproducts (Stein et al., 2016).

Corn germ meal (CGM) and corn gluten feed (CGF) are two main by-products obtained from corn starch extraction by wet milling (Figure 2B). CGM, the remaining portion of corn germ after oil removal, contains $30 \%$ protein, $18 \%$ starch, $12 \%$ cellulose, $2 \%$ ash, and $0.7 \%$ fat (Nielsen et al., 1979). CGF is produced by combining concentrated steepwater with the fiber during wet milling separation process, which typically contains $60 \%$ fiber and $20 \%$ protein. The low solubility and unbalanced AA composition of protein limit the application of CBs in the feed industry (Anderson et al., 2012). Solidstate fermentation in feedstock processing is an efficient biotechnological approach to improve nutritional value and increase nutrient bioavailability (Decimo et al., 2017; Wang et al., 2018a). Bacillus subtilis, Pichia kudriavzevii, and Lactobacillus plantarum were widely used SSF strains (Ni et al., 2017). Bacillus subtilis can degrade large molecular proteins to produce small peptides in SSF due to their capacity to secrete extracellular protease (Soares et al., 2005). Yeast (such as Pichia kudriavzevii and Saccharomyces cerevisiae) is most commonly used for agricultural byproduct SSF to obtain single-cell proteins (S) due to their low nutritional requirements, rapid growth, and high protein content (Hezarjaribi et al., 2016; Deng et al., 2020). The organic acids produced by Lactobacillus plantarum, mainly lactic acid, can reduce the $\mathrm{pH}$ of the fermentation system and inhibit the proliferation of some pathogenic bacteria and fungi (Missotten et al., 2015). In recent years, there have been many reports on the use of single bacteria to SSF agricultural byproducts, and a few study on the use of the abovementioned bacteria pairwise-combination fermentation to compare the fermentation effect. Our previous research shows that solid fermented soybean meal-corn mixture feed and distilled dried grain with soluble Bacillus subtilis and Lactobacillus plantarum can effectively improve their nutritional value and increase the content of small peptides and lactic acid (Shi et al., 2017; Wang et al., 2018b; Zhang et al., 2018; Zong et al., 2020). In addition, protease is widely used in SSF to degrade large molecular proteins to produce small peptides (Bedrosian and Kung, 2019). We hypothesized that using protease instead of extracellular protease-producing Bacillus subtilis to ferment with Lactobacillus plantarum and Pichia kudriavzevii would have a better fermentation effect.

In this study, a solid-state fermented feed system containing CBs, corn, soybean meal, and wheat bran was performed to gain a sufficient usage of CBs. To degrade fibers and produce digestible protein, Bacillus subtilis, Lactobacillus plantarum, and Pichia kudriavzevii were used for pairwise fermentation of CMF and reinforced by adding protease. Fermentation time, liquid ratio, and temperature would be traced to find better fermentation conditions and form a fermentation strategy.

\section{MATERIALS AND METHODS}

\section{Microorganisms and Enzymes}

Bacillus subtilis ZJU12-1 (CGMCC No: 12825) and Lactobacillus plantarum CWLP (CGMCC No: 1.510) were obtained from Chinese traditional pickled vegetables. Pichia kudriavzevii PKWF was obtained from grains of a Chinese local distiller. Bacillus subtilis ZJU12-1, Lactobacillus plantarum CWLP, and Pichia kudriavzevii PKWF were maintained on Luria broth (LB), de Man, Rogosa, and Sharp (MRS), and yeast extract peptone dextrose (YPD) plates preserved at $4^{\circ} \mathrm{C}$. Neutral protease was from Bacillus spp. (P3111; Sigma-Aldrich Corp.). CMF contains $20 \%$ CGM, $30 \%$ CGF, $30 \%$ corn, $15 \%$ soybean meal, and $5 \%$ wheat bran, which were obtained from the Cofine Bio-tech Co., Ltd. (Jiaxing, China).

\section{Preparation of Fermented Mixed Substrates}

The fermentation substrates were set as follows to obtain the optimal fermentation combination: B. subtilis ZJU12$1+P$. kudriavzevii PKWF, P. kudriavzevii $\mathrm{PKWF}+L$. plantarum CWLP, B. subtilis ZJU12-1 + L. plantarum CWLP, P. kudriavzevii PKWF + neutral protease, L. plantarum CWLP + neutral protease, and L. plantarum CWLP $+P$. kudriavzevii PKWF + neutral protease. Before fermentation, B. subtilis ZJU12-1 was cultured in LB liquid medium at $37^{\circ} \mathrm{C}$ for $12 \mathrm{~h}$. L. plantarum CWLP was cultured in MRS liquid medium at $37^{\circ} \mathrm{C}$ for $18 \mathrm{~h}$. P. kudriavzevii PKWF was cultured in YPD liquid medium at $37^{\circ} \mathrm{C}$ for $12 \mathrm{~h}$. The $100 \mathrm{~g}$ CMF was mixed and placed in a 500-ml Erlenmeyer flask, and sterile water was added to achieve a solid-liquid ratio $(1.5: 1 \mathrm{~g} / \mathrm{ml})$. The wet mixed CMF was inoculated with microbes $(7.0 \mathrm{log} \mathrm{cfu} / \mathrm{g})$ or protease $(50 \mathrm{U} / \mathrm{g})$ according to the fermentation combinations listed above. Then the flask was covered with a membrane (aerobic condition) and fermented at $37^{\circ} \mathrm{C}$. The control group of CMF was treated without different bacteria and neutral protease, and other fermentation conditions were consistent. Moist samples (approximately $100 \mathrm{~g}$ ) at 0,36 , and $72 \mathrm{~h}$ were collected to determine the numbers of microorganisms and microbial metabolites, and for 16S rRNA and ITS gene high-throughput sequencing, and the remaining samples were treated at $105^{\circ} \mathrm{C}$ for $30 \mathrm{~min}$ to prevent continuous fermentation. Then, the samples were dried at $65^{\circ} \mathrm{C}$ for $24 \mathrm{~h}$, cooled, and ground, and subjected to physicochemical analysis, SDS-PAGE.

\section{Optimization of Fermentation Conditions}

Based on the restriction of the fermentation conditions of SSF in actual scale production in China, the solidliquid ratios $(1.8: 1,1.5: 1$, and $1.2: 1 \mathrm{~g} / \mathrm{ml})$, fermentation 
temperatures $\left(27^{\circ} \mathrm{C}, 32^{\circ} \mathrm{C}\right.$, and $\left.37^{\circ} \mathrm{C}\right)$, and fermentation times $(24,48$, and $72 \mathrm{~h})$ were investigated with response surface analysis to optimize the parameters of the optimal fermentation, and the Design Expert software (Version 8.0.6, Stat-Ease Inc., Minneapolis, MN, United States) was used for the regression and graphical analysis of the experimental data obtained.

$M=a 0+a 1 \times A+a 2 \times B+a 3 \times C+a 4 \times A^{2}+a 5 \times B^{2}+a 6$ $\times C^{2}+a 7 \times A \times B+a 8 \times A \times C+a 9 \times B \times C . M$ is the predicted response; $a 0$ is the intercept term; $a 1, a 2$, and $a 3$ are the linear coefficients; $a 4, a 5$, and $a 6$ are the squared coefficients; and $a 7, a 8$, and $a 9$ are the interaction coefficients.

To further study the effect of anaerobic condition on CMF fermentation quality, we used the two-stage SSF method. Briefly, the two-stage SSF process includes two stages; at the first stage, CMF was used as the main fermented substrate, which was inoculated with an effective combination of Pichia kudriavzevii and neutral protease at aerobic fermentation for $36 \mathrm{~h}$; then at the second stage, Lactobacillus plantarum was inoculated into the first stage-fermented substrate at anaerobic fermentation for $36 \mathrm{~h}$.

\section{Chemical Analyses}

The dried samples of CMF were ground, sieved through a 1$\mathrm{mm}$ sieve, and then the DM, CP, AA, EE, CF, NDF, and ADF were analyzed as described by AOAC (2005). Determination of TCA-SP in samples was performed using the method proposed by Ovissipour et al. (2009).

\section{Microorganisms and Microbial Metabolites}

The $\mathrm{pH}$ and microbial counts were analyzed by the method of Wang et al. (2018b) with minor modifications. In brief, $5 \mathrm{~g}$ of wet samples was dissolved in $45 \mathrm{ml}$ of sterile water and placed on a shaker at $150 \mathrm{rpm}$ for $20 \mathrm{~min}$. The $\mathrm{pH}$ of the supernatant was measured with a $\mathrm{pH}$ meter (Mettler Toledo, Switzerland). The samples were diluted 10 -fold with sterile water for microbial counts. The viable count of $B$. subtilis was counted after culturing on LB agar for $24 \mathrm{~h}$ at $37^{\circ} \mathrm{C}$. The viable count of L. plantarum was counted after culturing on MRS agar for $48 \mathrm{~h}$ at $37^{\circ} \mathrm{C}$. The viable count of $P$. kudriavzevii was counted after culturing on YPD agar for $48 \mathrm{~h}$ at $37^{\circ} \mathrm{C}$.

The concentration of organic acids (acetic acid, propionic acid, butyric acid, and lactic acid) in each sample was separated and quantified using a gas chromatograph (GC; GC-14B, Shimadzu, Japan; capillary column $30 \mathrm{~m} \times 0.32 \mathrm{~mm} \times 0.25 \mu \mathrm{m}$ film thickness/VARIAN CP-3800, Varian, Palo Alto, CA, United States) as described by Franklin et al. (2002). In brief, the samples $(1 \mathrm{~g})$ were thawed and suspended in $2 \mathrm{ml}$ of distilled water in a screw-capped tube. After being vortexed, each sample was centrifuged $(12,000 \times g)$ at $4^{\circ} \mathrm{C}$ for $10 \mathrm{~min}$. The supernatant $(1 \mathrm{ml})$ was transferred into a 2 -ml centrifuge tube and mixed with $0.2 \mathrm{ml}$ of metaphosphoric acid and kept at $4^{\circ} \mathrm{C}$ for $30 \mathrm{~min}$. The mixtures were then centrifuged $(12,000 \times g)$ again at $4^{\circ} \mathrm{C}$ for $10 \mathrm{~min}$. Aliquots of the supernatant $(1 \mu \mathrm{l})$ were analyzed by GC.

\section{In vitro Digestibility}

In vitro two-stage enzymatic hydrolysis process was performed by the method of Sakamoto et al. (2008) with minor modifications. In short, CMF or FCMF (2 g) was added to a 150-ml Erlenmeyer flask, containing $50 \mathrm{ml}, 10,000 \mathrm{U} / \mathrm{ml}$ of pepsin (activity: 3,000 U/mg, Sigma) solution $(0.05 \mathrm{~mol} / \mathrm{L} \mathrm{KCl-HCl} \mathrm{buffer,} \mathrm{pH}$ 2.0), and incubated on a shaker at $37^{\circ} \mathrm{C}, 100 \mathrm{rpm}$ for $5 \mathrm{~h}$. The $\mathrm{pH}$ of the mixture was then adjusted to 6.8 with $1 \mathrm{~mol} / \mathrm{L} \mathrm{NaOH}$ and $1 \mathrm{~mol} / \mathrm{L} \mathrm{HCl}$, and $150 \mathrm{mg}$ of trypsin (activity: $250 \mathrm{U} / \mathrm{mg}$, Sigma) was added to the mixture and incubated on a shaker at $37^{\circ} \mathrm{C}, 100 \mathrm{rpm}$ for $5 \mathrm{~h}$. After digestion, $5 \mathrm{ml}$ of $20 \%$ sulfosalicylic acid was added to the mixture and settled for $30 \mathrm{~min}$. The digested slurry samples were centrifuged at 3,000 $\times g$ for $15 \mathrm{~min}$. Then the precipitate, washed with doubled-distilled water for several times and collected, dried at $105^{\circ} \mathrm{C}$, was used to analyze the content of $\mathrm{CP}$ and $\mathrm{AA}$. In vitro $\mathrm{CP}(\mathrm{AA})$ digestibility $(\%)=$ [original $\mathrm{CP}$ (AA) amount - residual CP (AA) amount]/original CP (AA) amount $\times 100 \%$.

\section{Microscopic Inspection}

Changes in the physical properties of the substrates before and after fermentation were examined by SEM according to the protocol of the Electronic Microscopy Center of Zhejiang University. The microstructures of CMF and FCMF were observed using a field-emission scanning electron microscope (KYKY-EM3200, China) at $\times 100, \times 1,000$, and $\times 3,000$ magnifications.

\section{Sodium Dodecyl Sulfate-Polyacrylamide Gel Electrophoresis}

The proteins in CMF and FCMF were extracted using the procedure described by Faurobert (1997). The gel running conditions were chosen according to the report of Meinlschmidt et al. (2016). In brief, 12\% polyacrylamide-separating gels were used for electrophoresis. Approximately $5 \mathrm{~g}$ of the protein sample was placed in each well, and the sample was separated at $55 \mathrm{mV}$ for $200 \mathrm{~min}$. The gel was stained with Coomassie Brilliant Blue (CBB) R-250 (Bio-Rad, United States) for $60 \mathrm{~min}$ and destained with $7 \%$ acetic acid.

\section{DNA Extraction and Illumina MiSeq Sequencing, and Metabolic Function Prediction}

Total microbial genomic DNA, including bacterial and fungal genomic DNA, was extracted from the 18 samples using the E.Z.N.A soil DNA kit (Omega Bio-Tek, Norcross, GA, United States). A NanoDrop 2000 UV-vis spectrophotometer (Thermo Scientific, Wilmington, DE, United States) and $1 \%$ agarose gel electrophoresis were used to analyze DNA content and quality.

The V3-V4 gene regions of the bacterial $16 \mathrm{~S}$ rRNA gene were amplified with primers $338 \mathrm{~F}$ $\left(5^{\prime}\right.$-ACTCCTACGGGAGGCAGCAG-3 $\left.=\right)$ and 806R $\left(5^{\prime}-\right.$ GGACTACHVGGGTWTCTAAT-3=). The primer sequences for the ITS2 region of the fungal ITS gene were ITS1F 
(5'-CTTGGTCATTTAGAGGAAGTAA) and ITS2R (5' GCTGCGTTCTTCATCGATGC). PCR was conducted as follows: $3 \mathrm{~min}$ of denaturation at $95^{\circ} \mathrm{C} ; 27$ cycles of $30 \mathrm{~s}$ at $95^{\circ} \mathrm{C}, 30 \mathrm{~s}$ of annealing at $55^{\circ} \mathrm{C}$, and $45 \mathrm{~s}$ of elongation at $72^{\circ} \mathrm{C}$; and a final extension at $72^{\circ} \mathrm{C}$ for $10 \mathrm{~min}$. The AxyPrep DNA gel extraction kit (Axygen Biosciences, Union City, CA, United States) and QuantiFluor-ST instrument (Promega, United States) were used to further extract, purify, and quantify the PCR products. The MiSeq platform (Shanghai Majorbio Biopharm Technology Co., Ltd.) was used to describe the bacterial community based on the gene segment from the V3-V4 and ITS2 portion of the rRNA gene. Subsequently, raw illumina FASTQ files were demultiplexed, quality filtered, and analyzed using Quantitative Insights into Microbial Ecology (QIIME v1.9.1). Raw fastq files were quality filtered by Trichromatic and merged by FLASH. Operational taxonomic unit (OTUs) were clustered with 97\% similarity cutoff using UPARSE (version 7.1). The taxonomy of each 16S rRNA gene sequence was analyzed using the RDP Classifier algorithm ${ }^{1}$ against the Greengenes $16 \mathrm{~S}$ rRNA database using a confidence threshold of $70 \%$. The assembled MiSeq sequences were submitted to the NCBI's Sequence Read Archive (SRA BioProject no. PRJNA730509) for open access. Estimates of diversity values for these samples using the Chao1, Shannon, and Simpson indexes for diversity estimation were calculated by rarefaction analysis. Good's coverage analysis was also performed. PCA and cluster analysis with the Ward method were conducted using the web server tool METAGENassist based on unweighted UniFrac distances. The main differentially abundant genera were selected by the LEfSe method ${ }^{2}$. To predict metabolic genes during the process, PICRUSt (see text footnote 2) was applied to obtain a functional profile from the 16S rRNA data. Prior to metagenome prediction, the OTUs of $16 \mathrm{~S}$ rRNA sequences were analyzed using PICRUSt. PICRUSt and KEGG were used to obtain functions for the genes that were predicted to be present in the samples and to assign the genes into metabolic pathways. Fungal communities were analyzed and classified by the FUNGuild online tool ${ }^{3}$.

\section{Statistical and Bioinformatics Analysis}

All assay data were analyzed using SPSS 20.0 software (SAS Inc., Chicago, IL, United States). One-way ANOVA and Duncan test were used to determine the difference between the mean values, and data are expressed as mean value \pm standard deviation (SD). The differences between the means of the treatments were considered significant at $p<0.05$. The heatmap package of $\mathrm{R}$ ( $\mathrm{R}$ Core Team, 2014) was applied to generate heat maps of genera and L3-predicted microbial gene functions. Bar plots were generated in GraphPad Prism 8 (San Diego, CA, United States). Multiple testing corrections of distinguished species and predicted metabolic functions during fermentation were employed using Welch's test and the Benjamini-Hochberg false-discovery rate (FDR) method for statistical analysis of metagenomic profiles (STAMP version 2.1.3).

\footnotetext{
${ }^{1}$ http://rdp.cme.msu.edu/

${ }^{2}$ https://huttenhower.sph.harvard.edu/galaxy/

${ }^{3}$ http://www.funguild.org/
}

\section{RESULTS}

\section{Selection of the Strain and Enzyme}

Based on the results of the single-factor experiment (Table 1), CMF fermented with P. kudriavzevii PKWF, L. plantarum CWLP, and neutral protease (CMFPLN) has the highest content of CP, TCA-SP, and EE compared with the other fermentation combinations, which were $9.5 \%, 22.1 \%$, and $38.1 \%$ higher than that of CMF, respectively. Furthermore, CF of CMFPLN is significantly lower than that of CMF $(p<0.05)$. These results indicate that the process of fermentation with $P$. kudriavzevii PKWF, L. plantarum CWLP, and neutral protease significantly improved the nutritional composition of CMF. In addition, CMFPLN has a more viable count of P. kudriavzevii PKWF and L. plantarum CWLP. The results above all suggest that CMFPLN may have the best fermentation potential.

\section{Optimal Fermentation Conditions of Corn Byproduct Mixture Feed Fermented With Pichia kudriavzevii PKWF, Lactobacillus plantarum CWLP, and Neutral Protease}

Box-Behnken design (BBD) was employed to optimize three variables: fermentation temperature (A), fermentation time (B), and solid-liquid ratio (C) of CMFPLN. Based on the response surface results (Figure 1) and multiple regression analysis of the experimental data, the following second-order polynomial equation between the viable count of $P$. kudriavzevii PKWF, L. plantarum CWLP, and the three variables during fermentation were found: the viable count of $P$. kudriavzevii $\mathrm{PKWF}=6.56+0.27 \times A+0.38 \times B+2.20 \times C+0.64 \times A \times B$ $+0.025 \times A \times C-0.015 \times B \times C-3.08 \times A^{2}-2.72 \times B^{2}-1.31$ $\times \quad C^{2}$, the viable count of $L$. plantarum $\mathrm{CWLP}=28.80-1.3 \times A+8.89 \times B+27.36 \times C+3.38 \times A \times B$ $+13.83 \times A \times C+7.10 \times B \times C-6.55 \times A^{2}-0.13 \times B^{2}+15.42$ $\times \quad C^{2}$. Similarly, second-order polynomial equation between the content of CP, TCA-SP, and the three variables during fermentation were found: the content of $\mathrm{CP}=23.41+0.47 \times A+0.34 \times B+0.65 \times C-0.046 \times A \times B+$ $0.52 \times A \times C+0.66 \times B \times C-0.60 \times A^{2}+0.20 \times B^{2}-0.22 \times C^{2}$, the content of TCA-SP $=40.63-1.45 \times A-1.35 \times B-1.46 \times C$ $-0.59 \times A \times B-2.76 \times A \times C-1.14 \times B \times C+1.73 \times A^{2}+2.06$ $\times B^{2}-0.91 \times C^{2}$.

By solving the regression equations above, the optimal condition of the three variables to obtain the maximum point of the model were calculated to be fermentation temperature at $32^{\circ} \mathrm{C}$, fermentation time of $50 \mathrm{~h}$, and a solid-liquid ratio of $1.2: 1 \mathrm{~g} / \mathrm{ml}$, with the corresponding viable count of $P$. kudriavzevii PKWF at $7.50 \times 10^{7} \mathrm{CFU} / \mathrm{g}$. Similarly, under the optimal conditions of fermentation temperature at $37^{\circ} \mathrm{C}$, fermentation time of $72 \mathrm{~h}$, and a solid-liquid ratio of $1.2: 1 \mathrm{~g} / \mathrm{ml}$, the viable count of L. plantarum CWLP reached the maximum value of $96.75 \times 10^{7} \mathrm{CFU} / \mathrm{g}$. The content of $\mathrm{CP}$ reached the maximum value of $25.86 \%$, which was the same as the optimal conditions for the maximum viable count of $L$. plantarum CWLP. In addition, 
TABLE 1 | Nutrient composition and microorganisms of corn byproducts mixture feed (CMF) and CMF fermented with different microbes and neutral protease (as air-dry basis).

\begin{tabular}{|c|c|c|c|c|c|c|c|}
\hline Items & CMF & CMFBP & CMFPL & CMFBL & CMFPN & CMFLN & CMFPLN \\
\hline DM, \% & $90.33 \pm 0.40$ & $91.46 \pm 0.48$ & $91.08 \pm 0.42$ & $90.84 \pm 0.56$ & $90.80 \pm 0.36$ & $91.96 \pm 0.22$ & $91.04 \pm 0.17$ \\
\hline $\mathrm{EE}, \%$ & $2.23 \pm 0.04 \mathrm{e}$ & $2.51 \pm 0.08 d$ & $2.59 \pm 0.03 c d$ & $2.72 \pm 0.06 c$ & $2.88 \pm 0.08 b$ & $2.36 \pm 0.08 \mathrm{e}$ & $3.08 \pm 0.14 a$ \\
\hline $\mathrm{CP}, \%$ & $22.27 \pm 0.35 d$ & $23.60 \pm 0.40 b$ & $23.42 \pm 0.48 b c$ & $22.85 \pm 0.25 c$ & $23.08 \pm 0.14 b c$ & $23.29 \pm 0.28 b c$ & $24.39 \pm 0.24 a$ \\
\hline TCA-SP, \% & $37.45 \pm 0.47 e$ & $44.22 \pm 0.31 b c$ & $42.78 \pm 0.27 d$ & $43.65 \pm 0.39 c$ & $44.00 \pm 0.29 c$ & $44.72 \pm 0.24 b$ & $45.74 \pm 0.13 a$ \\
\hline $\mathrm{CF}, \%$ & $6.11 \pm 0.32 a$ & $5.33 \pm 0.39 b c$ & $5.51 \pm 0.42 b$ & $5.18 \pm 0.14 \mathrm{bc}$ & $5.37 \pm 0.32 b c$ & $5.12 \pm 0.10 \mathrm{bc}$ & $4.91 \pm 0.16 c$ \\
\hline $\mathrm{pH}$ & $6.40 \pm 0.03 a$ & $6.22 \pm 0.10 \mathrm{a}$ & $4.67 \pm 0.09 b$ & $4.69 \pm 0.17 b$ & $6.21 \pm 0.12 a$ & $4.55 \pm 0.07 b$ & $4.52 \pm 0.18 b$ \\
\hline \multicolumn{8}{|l|}{ Microorganism, $\times 10^{7} \mathrm{CFU} / \mathrm{g}$} \\
\hline Bacillus subtilis ZJU12-1 & - & $82.00 \pm 5.13$ & - & $5.33 \pm 8.19$ & - & - & - \\
\hline Pichia kudriavzevii PKWF & - & $1.80 \pm 0.61$ & $2.10 \pm 0.44$ & - & $1.71 \pm 0.61$ & - & $2.73 \pm 0.65$ \\
\hline Lactobacillus plantarum CWLP & - & - & $16.67 \pm 4.51$ & $14.67 \pm 4.51$ & - & $16.00 \pm 0.44$ & $23.00 \pm 6.25$ \\
\hline
\end{tabular}

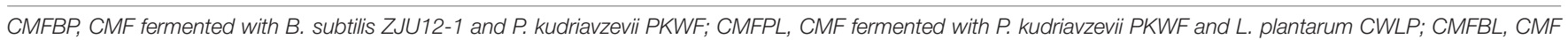

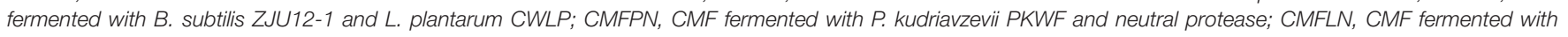
L. plantarum CWLP and neutral protease; CMFPLN, CMF fermented with P. kudriavzevii PKWF, L. plantarum CWLP, and neutral protease.

Values are mean $\pm S D, n=3$. Means followed with different superscript letters $(a, b)$ within each line are significantly different $(p<0.05)$.

under the optimal conditions of fermentation temperature at $37^{\circ} \mathrm{C}$, fermentation time of $24 \mathrm{~h}$, and solid-liquid ratio of $1.8: 1 \mathrm{~g} / \mathrm{ml}$, the content of TCA-SP reached the maximum value of $46.93 \%$. In order to verify the optimization results, a verification experiment was conducted to show that the viable count of $P$. kudriavzevii PKWF, L. plantarum CWLP, the content of CP, and TCA-SP in their optimum conditions were $7.82 \times 10^{7} \mathrm{CFU} / \mathrm{g}, 90.21 \times 10^{7} \mathrm{CFU} / \mathrm{g}, 25.52 \%$, and $46.21 \%$, respectively, which indicated that the model was satisfactory and practicable.

\section{Two-Stage Solid-State Fermentation}

Two-stage solid-stage fermentation was conducted and the process is presented in Figure 2A. The nutrient contents of CMF and CMF by two-stage solid-stage fermentation (FCMF) are presented in Table 2. Compared with CMF, the fermented CMF contained more CP, TCA-SP, and EE, which were augmented $(p<0.05)$ by approximately $14.28 \%, 25.33 \%$, and $42.119 \%$, respectively. Furthermore, the content of CF, ADF, and NDF were decreased $(p<0.05)$ by $29.10 \%, 10.43 \%$, and $18.15 \%$, respectively. In this study, the content of amylose and total starch were decreased dramatically after fermentation $(p<0.05)$. In addition, fermentation with inoculated microorganisms and neutral protease also affected the AA composition in CMF. In the present research, three indispensable AA (His, Ile, and Phe), two dispensable AA (Ser and Ala), and total AA significantly increased in FCMF compared with CMF. In addition, except for Asp, most AA showed an increase trend after fermentation. These results of the two-stage SSF were similar to the response surface analysis, which indicated that the oxygen was exhausted at the aerobic fermentation process and formed an anaerobic condition in the mixed substrates. This process is familiar with the two-stage SSF.

\section{Microorganisms and Microbial Metabolites of Fermented Corn Byproduct Mixture Feed}

To further evaluate the nutritional properties of FCMF, we determined the microorganisms and microbial metabolites after fermentation, and the results are presented in Table 3. After fermentation, the viable counts of $P$. kudriavzevii PKWF and L. plantarum CWLP in FCMF reached $6.95 \times 10^{7}$ and $90.21 \times 10^{7} \mathrm{CFU} / \mathrm{g}$, respectively. The $\mathrm{pH}$ of $\mathrm{CMF}$ decreased from 6.42 to 4.54 , which was mainly caused by organic acids produced by L. plantarum CWLP. The acetic acid, propionic acid, butyric acid, and lactic acid in FCMF were increased by 6.72, 20.83, 21.00, and 5.64 times, respectively.

\section{In vitro Digestibility of Fermented Corn Byproduct Mixture Feed}

The results of the digestibility of CMF and FCMF are presented in Table 4. The in vitro digestibility of DM and CP in FCMF were notably improved by $18.98 \%$ and $16.62 \%$. In addition, the in vitro digestibility of 14 AA, including 9 essential AAs (Arg, His, Ile, Leu, Met, Lys, Thr, Phe, and Val) and 5 dispensable AA (Ser, Glu, Ala, Tyr, and Cys) were significantly enhanced. Furthermore, after $72 \mathrm{~h}$ of fermentation, the digestibility of the average indispensable AA, average dispensable AA, and total AA were enormously improved by approximately $1.19,1.17$, and 1.13 times, respectively.

\section{Electrophoresis and Microscopic Observation}

In the present study, the protein profiles of CMF were distributed in the range of $20-100 \mathrm{kDa}$ (Figure 2C). However, in the fermentation with P. kudriavzevii PKWF, L. plantarum CWLP, and neutral protease for $72 \mathrm{~h}$, the protein profile corresponding to multiple bands in the range of $55-100 \mathrm{kDa}$ in FCMF were completely degraded. After $72 \mathrm{~h}$ of fermentation, the protein profile corresponding to multiple bands in the range of 30$50 \mathrm{kDa}$ in FCMF were obviously degraded. In addition, the content of small peptides $(<25 \mathrm{kDa})$ was significantly increased in FCMF compared with CMF.

Scanning electron microscopy (SEM) was applied to investigate the physical structures of CMF and FCMF. Figure 2D shows the surface images of CMF and FCMF at magnification factors of $\times 100, \times 1,000$, and $\times 3,000$. After $72 \mathrm{~h}$ of fermentation, more fragmental structures were detected. At the same 
A $\mathbf{a}$

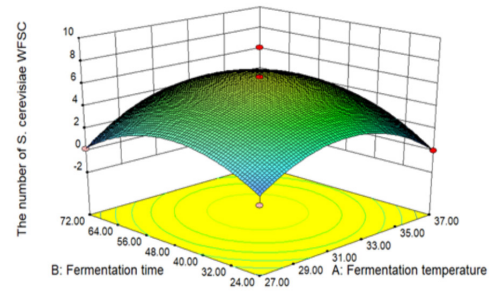

B a

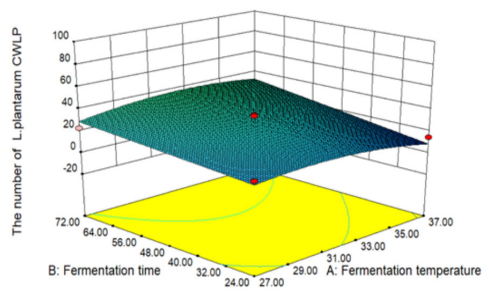

C a

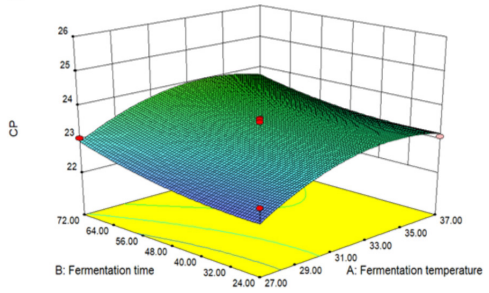

D a

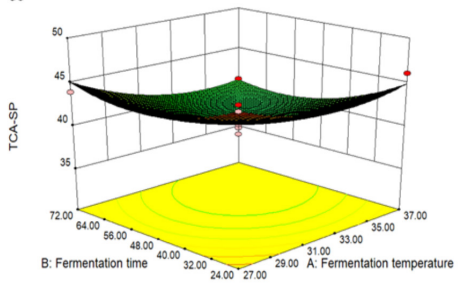

b

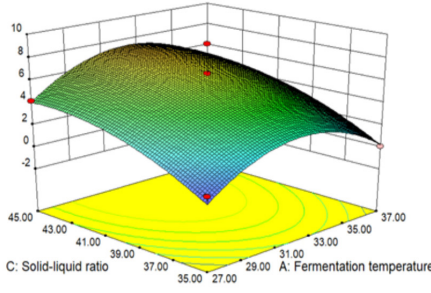

b
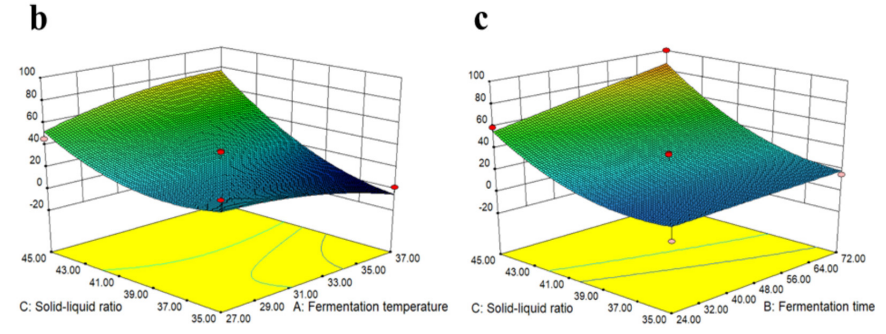

b
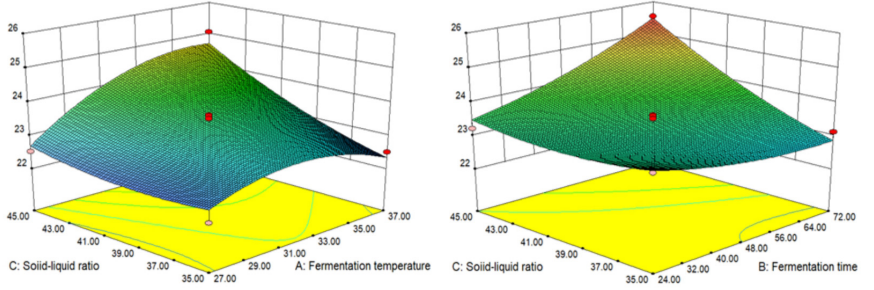

b

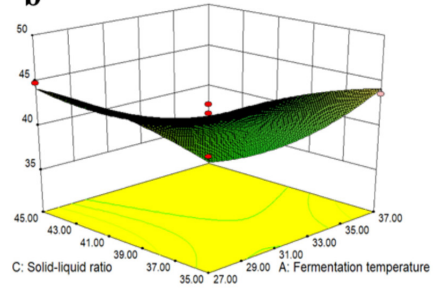

c

c

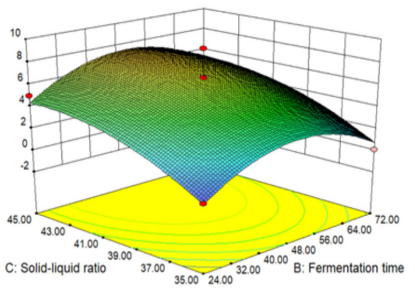

c

c

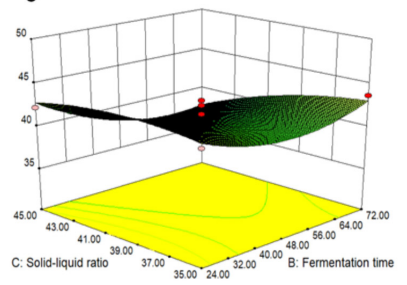

FIGURE 1 | The response surface and contour plots showing the interactive effects of fermentation conditions on the viable count of Pichia kudriavzevii PKWF (A), the viable count of Lactobacillus plantarum CWLP (B), crude protein (CP) (C), and trichloroacetic acid-soluble protein (TCA-SP) (D) of corn byproduct mixture feed fermented with P. kudriavzevii PKWF, L. plantarum CWLP, and neutral protease (CMFPLN) [(a) fermentation time and fermentation temperature; (b) solid-liquid ratio and fermentation temperature; (c) solid-liquid ratio and fermentation time].

magnification factor, CGM and CGF in CMF had relatively large, compact, and smooth-faced structures, while the two main CBs in FCMF had smaller cracked structures and large holes. Besides, the surface of FCMF gathered more inoculated microbes.

\section{Changes in the Bacterial Community}

Overall, 229,415 high-quality sequences were collated. Additionally, the general $16 \mathrm{~S}$ rRNA OTU numbers reached 798 based on $97 \%$ sequence similarity (Table 5). Combined with Good's coverage index $(99.6 \% \pm 0.00 \%$, data not shown), the results suggested that the samples exhibited abundant OTU coverage and that the sequencing depth was sufficient for analysis of the actual structure of the bacterial community during SSF. Figure 3A shows that the number of OTUs increased after the addition of $P$. kudriavzevii PKWF during the initial $36 \mathrm{~h}$. In contrast, the number of OTUs decreased after the following $36 \mathrm{~h}$ of anaerobic fermentation. A Venn plot (Figure 3B) shows the common and unique OTUs in the groups. Fifty-eight OTUs as core genera were shared by all of the groups. The principal component analysis (PCA) plot (Figure 3C) shows that samples at 0,36 , and $72 \mathrm{~h}$ were well resolved and obviously distinct, while the OTU sample at $36 \mathrm{~h}$ exhibited fewer differences than others of the same group. In general, more than four bacterial phyla were found in all the samples (Figure 3D). In 
TABLE 2 | Nutrient composition of CMF and fermented CMF (FCMF) (as air-dry basis).

\begin{tabular}{|c|c|c|c|c|c|}
\hline Items & CMF & FCMF & Items & CMF & FCMF \\
\hline DM, \% & $90.33 \pm 0.02 a$ & $91.67 \pm 0.02 a$ & Indispensable AA,\% & & \\
\hline EE, \% & $2.28 \pm 0.14 b$ & $3.24 \pm 0.11 a$ & Arg & $1.74 \pm 0.02 a$ & $1.75 \pm 0.01 a$ \\
\hline $\mathrm{CP}, \%$ & $22.33 \pm 0.13 b$ & $25.52 \pm 0.18 a$ & His & $0.59 \pm 0.02 b$ & $0.66 \pm 0.02 a$ \\
\hline TCA-SP, \% & $37.26 \pm 1.00 b$ & $46.70 \pm 0.78 a$ & Ile & $1.38 \pm 0.01 b$ & $1.55 \pm 0.06 a$ \\
\hline $\mathrm{CF}, \%$ & $6.70 \pm 0.17 a$ & $4.05 \pm 0.09 b$ & Leu & $0.74 \pm 0.01 a$ & $0.76 \pm 0.00 a$ \\
\hline ADF, \% & $10.64 \pm 0.08 a$ & $9.53 \pm 0.17 b$ & Lys & $0.74 \pm 0.01 a$ & $0.76 \pm 0.00 a$ \\
\hline NDF, \% & $28.71 \pm 0.13 a$ & $23.50 \pm 0.25 b$ & Met & $0.16 \pm 0.01 a$ & $0.18 \pm 0.01 a$ \\
\hline Total starch, \% & $14.49 \pm 0.11 a$ & $13.96 \pm 0.05 b$ & Phe & $0.75 \pm 0.01 b$ & $0.83 \pm 0.03 a$ \\
\hline Amylopectin, \% & $10.40 \pm 0.14 a$ & $10.34 \pm 0.07 a$ & Thr & $0.38 \pm 0.01 a$ & $0.41 \pm 0.01 a$ \\
\hline \multirow[t]{11}{*}{ Amylose, \% } & $4.09 \pm 0.05 a$ & $3.62 \pm 0.06 b$ & Val & $0.78 \pm 0.01 a$ & $0.85 \pm 0.05 a$ \\
\hline & & & Dispensable AA,\% & & \\
\hline & & & Asp & $1.74 \pm 0.00 a$ & $1.71 \pm 0.01 a$ \\
\hline & & & Ser & $1.41 \pm 0.01 b$ & $1.54 \pm 0.00 a$ \\
\hline & & & Glu & $4.61 \pm 0.07 a$ & $4.76 \pm 0.07 a$ \\
\hline & & & Gly & $0.62 \pm 0.01 a$ & $0.64 \pm 0.00 a$ \\
\hline & & & Ala & $1.32 \pm 0.01 b$ & $1.48 \pm 0.00 \mathrm{a}$ \\
\hline & & & Cys & $0.21 \pm 0.01 a$ & $0.23 \pm 0.00 a$ \\
\hline & & & Tyr & $1.19 \pm 0.03 a$ & $1.26 \pm 0.05 a$ \\
\hline & & & Pro & $1.41 \pm 0.00 \mathrm{a}$ & $1.37 \pm 0.03 a$ \\
\hline & & & Total AA & $19.61 \pm 0.13 b$ & $20.67 \pm 0.12 a$ \\
\hline
\end{tabular}

Values were mean $\pm S D, n=3$. Means followed with different superscript letters $(a, b)$ within each line are significantly different ( $p<0.05$ ).

TABLE 3 | Microorganism and microbial metabolites of CMF and FCMF.

\begin{tabular}{lrr}
\hline Items & \multicolumn{1}{c}{ CMF } & \multicolumn{1}{c}{ FCMF } \\
\hline Organic acids, $\mathrm{mg} / 100 \mathrm{~g}$ & & \\
Acetic acid & $22.07 \pm 0.04 \mathrm{~b}$ & $148.22 \pm 0.52 \mathrm{a}$ \\
Propionic acid & $0.06 \pm 0.01 \mathrm{~b}$ & $1.25 \pm 0.03 \mathrm{a}$ \\
Butyric acid & $0.18 \pm 0.01 \mathrm{~b}$ & $3.78 \pm 0.09 \mathrm{a}$ \\
Lactic acid & $26.53 \pm 0.08 \mathrm{~b}$ & $149.61 \pm 0.09 \mathrm{a}$ \\
pH & $6.42 \pm 0.11 \mathrm{a}$ & $4.54 \pm 0.15 \mathrm{~b}$ \\
Microorganism, $10^{7} \mathrm{CFU} / \mathrm{g}$ & & \\
P. kudriavzevii PKWF & - & $6.95 \pm 0.60$ \\
L. plantarum WCLP & - & $90.21 \pm 8.40$ \\
\hline
\end{tabular}

Values were mean $\pm S D, n=3$. Means followed with different superscript letters $(a, b)$ within each line are significantly different $(p<0.05)$.

the CMF samples, Cyanobacteria and Proteobacteria accounted for $96.96 \% \pm 0.10 \%$ of the sequences. However, as fermentation progressed, Firmicutes rapidly became the primary members of the community, accounting for approximately $99 \%$ of the sequences. With regard to the changes in bacterial community structure, the results at the gene level were similar to those at the phylum level (Figure 3E). Unfermented materials contained various native bacteria, including pathogens such as Enterobacter spp. and Clostridium spp. As the overall fermentation progressed, the predominant bacteria changed from Cyanobacteria and Proteobacteria to Lactobacillus spp.

Furthermore, the linear discriminant analysis (LDA) effect size (LEfSe) results showed significantly different taxonomy among different fermentation time points (Figure 3F). After $36 \mathrm{~h}$ of aerobic fermentation, the abundances of the genera Bacillus
TABLE 4 | In vitro crude protein (CP) and amino acid (AA) digestibility (\%) of CMF and FCMF.

\begin{tabular}{|c|c|c|}
\hline Items & CMF & FCMF \\
\hline DM, \% & $48.89 \pm 0.37 b$ & $58.17 \pm 1.64 a$ \\
\hline $\mathrm{CP}, \%$ & $67.34 \pm 0.70 b$ & $78.53 \pm 0.51 a$ \\
\hline \multicolumn{3}{|c|}{ Indispensable AA, \% } \\
\hline Arg & $64.50 \pm 1.02 b$ & $73.71 \pm 4.75 a$ \\
\hline His & $66.11 \pm 3.13 b$ & $79.37 \pm 3.18 a$ \\
\hline lle & $52.58 \pm 1.30 b$ & $66.33 \pm 4.15 a$ \\
\hline Leu & $57.25 \pm 1.19 b$ & $64.92 \pm 2.19 a$ \\
\hline Lys & $50.67 \pm 1.53 b$ & $60.67 \pm 3.06 a$ \\
\hline Met & $52.81 \pm 1.51 b$ & $58.66 \pm 0.60 a$ \\
\hline Phe & $63.61 \pm 0.54 b$ & $76.81 \pm 1.92 \mathrm{a}$ \\
\hline Thr & $50.4 \pm 1.48 b$ & $62.21 \pm 1.15 a$ \\
\hline Val & $51.86 \pm 1.47 b$ & $65.91 \pm 2.59 a$ \\
\hline \multicolumn{3}{|c|}{ Dispensable AA, \% } \\
\hline Asp & $85.53 \pm 0.19 a$ & $81.76 \pm 1.59 b$ \\
\hline Ser & $62.57 \pm 1.76 b$ & $74.65 \pm 1.10 a$ \\
\hline Glu & $79.75 \pm 1.51 b$ & $91.08 \pm 1.94 a$ \\
\hline Gly & $61.44 \pm 0.99 a$ & $60.44 \pm 1.97 a$ \\
\hline Ala & $56.46 \pm 1.13 b$ & $67.61 \pm 1.96 a$ \\
\hline Cys & $49.86 \pm 1.29 b$ & $59.75 \pm 4.25 a$ \\
\hline Tyr & $55.35 \pm 3.34 b$ & $63.55 \pm 2.96 a$ \\
\hline Pro & $66.91 \pm 1.41 a$ & $68.83 \pm 1.56 a$ \\
\hline Total AA, \% & $66.20 \pm 0.31 b$ & $74.94 \pm 1.27 a$ \\
\hline
\end{tabular}

Values were mean $\pm S D, n=3$. Means followed with different superscript letters $(a, b)$ within each line are significantly different $(p<0.05)$.

and Xanthobacteraceae increased significantly. After $36 \mathrm{~h}$ of anaerobic fermentation, Paenibacillus spp., Pantoea spp., and Lactobacillales were predominant. 

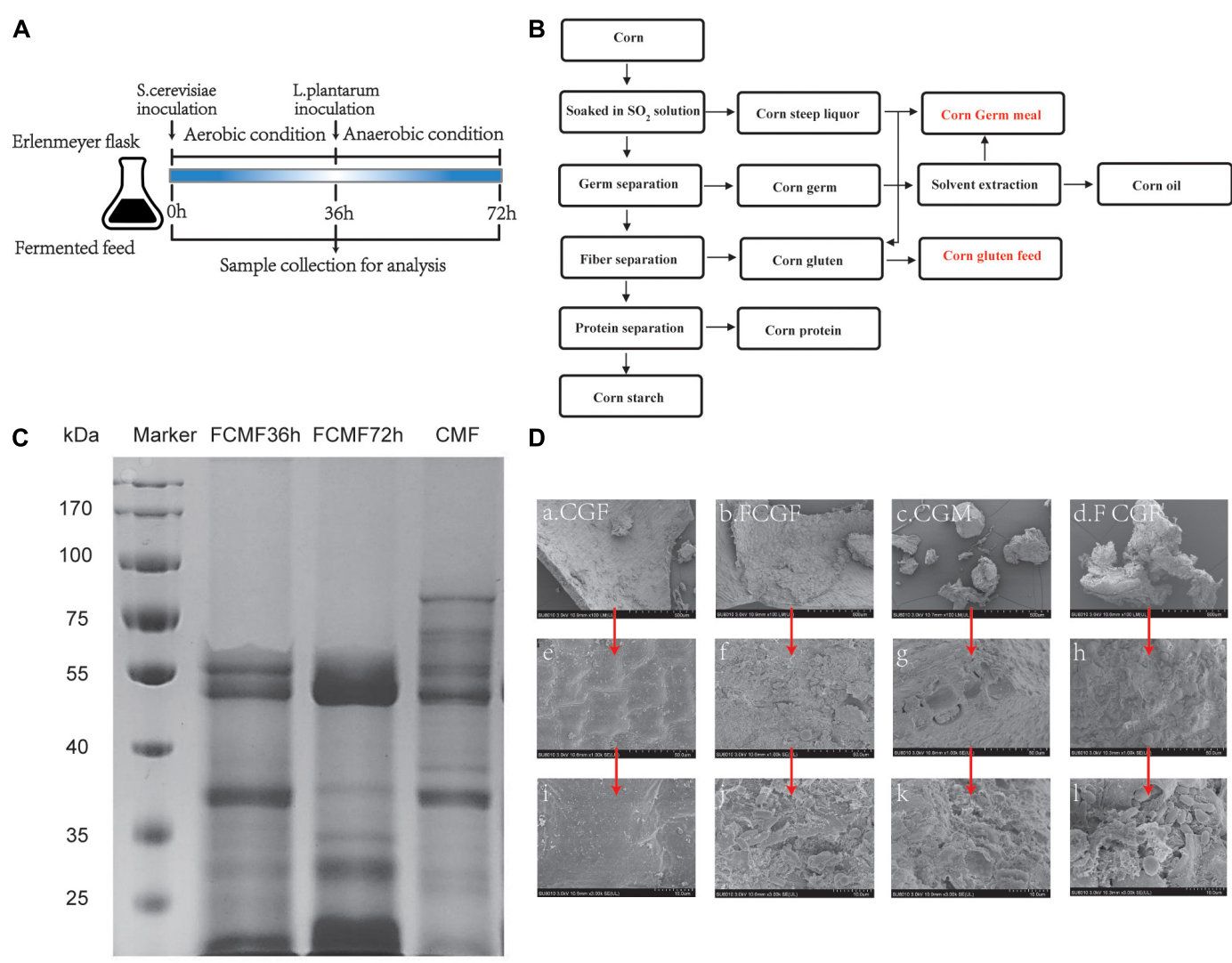

FIGURE 2 | Experimental design, electrophoresis, and scanning electron microscopy (SEM) image of corn byproduct mixture feed (CMF) and fermented CMF (FCMF). (A) Experimental design. (B) Simplified process of corn wet milling for starch production and its byproducts. (C) Sodium dodecyl sulfate-polyacrylamide gel electrophoresis (SDS-PAGE) of FCMF at fermentation times of 0, 36, and $72 \mathrm{~h}$. (D) SEM images of CMF and FCMF after $72 \mathrm{~h}$ of fermentation at $\times 100$ (a-d), $\times 1,000$ (e-h), and $\times 3,000$ (i-l) fold magnifications.

\section{Changes in the Fungal Community}

Full of 644,350 high-quality sequences were collated byITS Genes Amplification, and the general operational taxonomic unit (OTU) numbers reached 547 based on 95\% sequence similarity (Table 6). Combined with Good's coverage index $(99.7 \% \pm 0.00 \%$, data not shown), the results indicated that the samples exhibited abundant OTU coverage and that the sequencing depth was adequate for analysis of the actual structure of the fungal community during SSF. Figure $\mathbf{4 A}$ shows that the number of observed OTUs decreased after the addition of P. kudriavzevii PKWF during the first stage, then the number of observed OTUs decreased continuously after the following $36 \mathrm{~h}$ of anaerobic fermentation. A Venn plot (Figure 4B) shows the common and unique OTUs in the groups. Twenty-three OTUs as core genera were presented by all of the groups. The PCA plot (Figure 4C) illustrates that the samples between 0 and $36 \mathrm{~h}$ were significant resolved and obviously distinct, while the OTUs sample at 36 and $72 \mathrm{~h}$ exhibited fewer differences than those of the other samples. In general, more than three fungal phyla were found in all the samples (Figure 4D). In the CMF samples, Ascomycota, unclassified_k_Fung, and Basidiomycota occupied $97.96 \% \pm 0.10 \%$ of the sequences. As fermentation progressed, Ascomycota became the predominant member of the community, accounting for approximately $99 \%$ of the sequences. When it comes to the changes in fungal community structure, the results at the gene level were similar to those at the phylum level (Figure 4E). Unfermented feed contained various native fungi, including pathogens such as Colletotrichum and Fusarium. As the overall fermentation progressed, the predominant fungi were kept unchanged with Ascomycota.

Furthermore, the linear discriminant analysis (LDA) effect size (LEfSe) results showed significantly different taxonomy among different fermentation time points (Figure 4F). After $72 \mathrm{~h}$ of fermentation, the abundances of the OTU8 (P. kudriavzevii) increased significantly.

\section{Bacterial Metabolism of Fermented Mixed Substrates}

The microbial metabolic functions presented in Figure 5 were obtained based on the Clusters of Orthologous Groups of proteins (COG) and Kyoto Encyclopedia of Genes and Genomes (KEGG) pathway database. Figure 5A shows the changes of COGs in three different fermentation time points, with the fermentation process, proteins related to metabolism functions $(\mathrm{G}, \mathrm{F})$ and information storage and processing functions $(\mathrm{K})$ improved significantly; however, the functions of cellular 

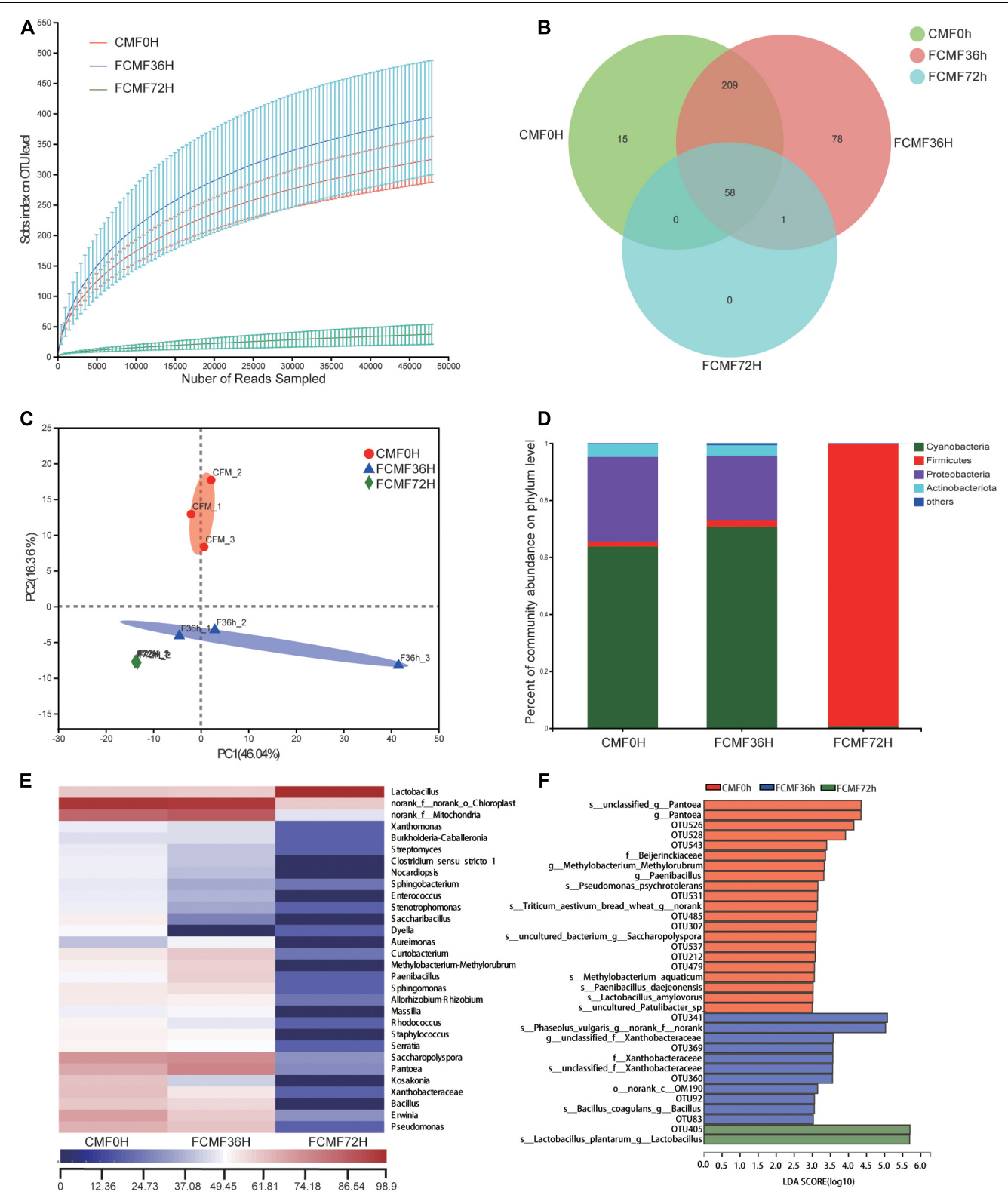

FIGURE 3 | Microbial diversity and bacterial community structure during two-stage solid-state fermentation (SSF) $(n=3)$. (A) Observed operational taxonomic unit (OTU) line chart. (B) Venn diagram representing the common and unique OTUs found at each fermentation time point. (C) Principal-component (PC) analyses of samples conducted based on unweighted UniFrac distanced. (D,E) Phylum-level (D) and genus-level (E) compositions of the bacterial community in FCFM. (F) Linear discriminant analysis (LDA) effect size (LEFSe) histogram showing the LDA scores (>3.0) computed for features at the OTU level. Letters indicate the taxonomy of the bacteria: $p$, phylum, c, class; o, order; f, family; g, genus.

processes and signaling $(\mathrm{O}, \mathrm{T}, \mathrm{U}, \mathrm{N}, \mathrm{Z})$ decreased from 0 to $72 \mathrm{~h}$. A majority of the predicted protein sequences ranged from $17.34 \% \pm 0.02 \%$ to $0.05 \% \pm 0.00 \%$ at the three time points among six different metabolic functions (Figure 5B), which represented different pathways (Figure 5C). Notably, carbohydrate metabolism, energy metabolism, and membrane transport accounted for more than $10 \%$ of the enriched pathways throughout the fermentation period. Furthermore, the sequences related to membrane transport, carbohydrate metabolism, energy metabolism, metabolism of cofactors and vitamins, nucleotide metabolism, and environmental adaptation were significantly enriched during intact fermentation process $(p<0.00)$.

At level 3 of the microbial gene functions of bacteria, some differences in efficiency were observed during SSF (Figure 5D). The abundance of a majority of the genes assigned to AA metabolism (cysteine and methionine metabolism, phenylalanine, tyrosine, and tryptophan biosynthesis) and carbohydrate metabolism (glycolysis/gluconeogenesis pyruvate metabolism, amino sugar and nucleotide sugar metabolism, fructose and mannose metabolism, pentose phosphate pathway, 
TABLE 5 | Characteristics of amplicon libraries in the bacteria community.

\begin{tabular}{|c|c|c|c|c|}
\hline \multirow[b]{2}{*}{ Characteristic } & \multicolumn{3}{|c|}{ Data for samples at time (h) } & \multirow[b]{2}{*}{ Total no. } \\
\hline & CFM O h & FCMF 36 h & FCMF 72 h & \\
\hline No. of sequences & $59,862 \pm 9,815$ & $54,342 \pm 5,696$ & $57,857 \pm 6080$ & 229,415 \\
\hline No. of operational taxonomic units (OTUs) & $405 \pm 29 A$ & $406 \pm 105 A$ & $41 \pm 20 B$ & 798 \\
\hline Chao1 index & $456 \pm 64 A$ & $489 \pm 69 A$ & $89 \pm 21 B$ & \\
\hline Shannon index & $1.69 \pm 0.19 A$ & $1.75 \pm 0.57 A$ & $0.06 \pm 0.01 B$ & \\
\hline Simpson index & $0.39 \pm 0.11 A$ & $0.32 \pm 0.11 A$ & $0.98 \pm 0.01 B$ & \\
\hline
\end{tabular}

Means with different letters in each row differ at $p<0.05$.

TABLE 6 | Characteristics of amplicon libraries in the fungal community.

\begin{tabular}{|c|c|c|c|c|}
\hline \multirow[b]{2}{*}{ Characteristic } & \multicolumn{3}{|c|}{ Data for samples at time (h) } & \multirow[b]{2}{*}{ Total no. } \\
\hline & CFM O h & FCMF 36 h & FCMF 72 h & \\
\hline No. of sequences & $69,999 \pm 1,237$ & $72,531 \pm 2,410$ & $72,252 \pm 1,752$ & 644350 \\
\hline No. of OTUs & $136 \pm 35 A$ & $31 \pm 25 B$ & $14 \pm 8 B$ & 547 \\
\hline Chao1 index & $148 \pm 28 A$ & $40 \pm 27 B$ & $23 \pm 62 B$ & \\
\hline Shannon index & $2.26 \pm 0.31 A$ & $0.10 \pm 0.04 B$ & $0.81 \pm 1.09 B$ & \\
\hline Simpson index & $0.17 \pm 0.05 B$ & $0.96 \pm 0.01 A$ & $0.97 \pm 0.00 A$ & \\
\hline
\end{tabular}

Means with different letters in each row differ at $p<0.05$.

and propanoate metabolism) increased dramatically during the fermentation process $(p<0.05)$. Similarly, the genes associated with membrane transporter, such as $\mathrm{ABC}$ transporters and phosphotransferase system (PTS), were markedly enriched by the fermentation $(p<0.05)$. All these gene functions that improved were attributed to using $L$. plantarum during the second stage of fermentation. In contrast, the abundances of most genes related to glycan biosynthesis and metabolism and energy metabolism decreased with fermentation. Interestingly, the abundance of genes involved in global and overview maps (carbon metabolism) decreased during the aerobic fermentation period, while a considerable increase was observed following anaerobic fermentation.

As expected, the gene functions related to $P$. kudriavzevii were improved after the addition of $P$. kudriavzevii PKWF and reduced during the second-stage fermentation. The gene function prediction of the fungal community is presented in Figure 6. Fungal communities were analyzed by the FUNGuild online tool (see text footnote 3). In general, more than six fungal function groups were inferred by FUNGuild (Figure 6A). After adding $P$. kudriavzevii, the main fungal function group was Saprotroph, and it continued to the end of fermentation. In addition, the fungal functional groups inferred by FUNGuild, indicated to us that the unfermented CMF contain the animal pathogen and plant pathogen; in contrast, the fermented CMF could inhibit these pathogenic microbes and improve the safety and quality of CMF, and the level 3 KEGG ortholog functional predictions of the relative abundances exhibited several changes of key enzymes (Figure 6B). Adenosine triphosphatase, ubiquitinyl hydrolase 1, benzoate 4-monooxygenase, xenobiotic-transporting ATPase, and tetrahydrofolate synthase were significantly enriched during the intact fermentation process $(p<0.00)$, while peptidylprolyl isomerase, DNA-directed RNA polymerase, proteasome endopeptidase complex, L-arabinose isomerase, glucan 1,4-alpha-glucosidase, $\mathrm{H}(+)$-transporting two-sector ATPase, histone acetyltransferase, and beta-glucosidase were decreased by adding L. plantarum CWLP.

\section{DISCUSSION}

In recent years, there have been many reports on the positive effects of bacteria or fungi (such as P. kudriavzevii and L. plantarum, etc.) and their metabolites in fermented feed. On the one hand, these microbes secrete a series of enzymes that effectively degrade anti-nutritional factors to improve the nutrient value of the feed materials (Arevalo-Villena et al., 2017). Besides, microorganisms and their functional metabolites, such as organic acids, cell wall polysaccharides, etc., can significantly improve the immune function of animals and inhibit the proliferation of pathogenic microorganisms, thereby maintaining the health of the animals (Fukuda et al., 2011; Zhu et al., 2014; Chen and Stappenbeck, 2019). Bacillus spp., Lactobacillus spp., and yeast were widely used in feed fermentation. However, the organic acids produced by Lactobacillus spp. would limit the activity of Bacillus spp. and, thus, inhibit its secretion of proteases (Wong and Chen, 1988). In the present study, we found that fermentation of P. kudriavzevii PKWF, L. plantarum CWLP, and neutral protease had the positive effect on improving $\mathrm{CP}$ and TCA-SP of CBs through single-factor experiments, which indicated that the role of Bacillus spp. in degrading proteins into TCA-SP could be replaced by neutral proteases. 

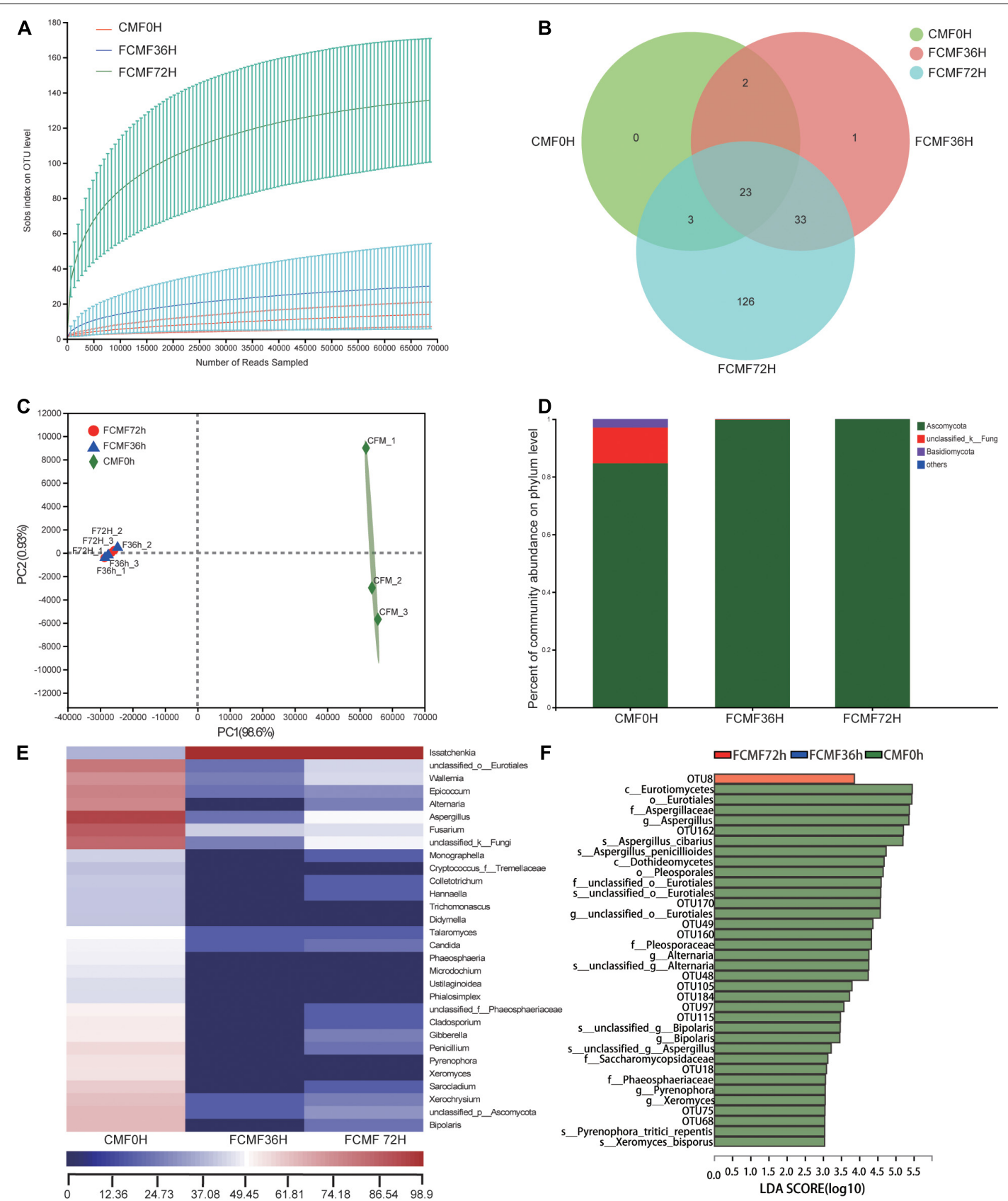

FIGURE 4 | Microbial diversity and fungal community structure during two-stage SSF $(n=3)$. (A) Observed OTU line chart. (B) Venn diagram representing the common and unique OTUs found at each fermentation time point. (C) Principal component analyses (PCA) of samples conducted based on unweighted UniFrac distanced. (D,E) Phylum-level (D) and genus-level (E) compositions of the fungal community in FCFM. (F) LEFSe histogram showing the LDA scores (>3.0) computed for features at the OTU level. Letters indicate the taxonomy of the bacteria: p, phylum, c, class; o, order; f, family; g, genus.

Response surface analysis is an effective way to investigate the interaction between different factors during fermentation. Compared with the previous report (Li et al., 2019), the optimized fermentation conditions of soybean meal by response surface analysis were fermentation temperature $\left(30^{\circ} \mathrm{C}\right)$, fermentation time $(72 \mathrm{~h})$, and solid-liquid ratio $(1: 3.5 \mathrm{~g} / \mathrm{ml})$; the protein hydrolysis of fermented soybean meal could reach to $10.05 \%$ by Neurospora crassa under the fermentation conditions. In our research, under the fermentation conditions of $32^{\circ} \mathrm{C}$, solid-liquid ratio $(1.2: 1 \mathrm{~g} / \mathrm{ml})$, and $50 \mathrm{~h}$, the proliferation of P. kudriavzevii PKWF reached its maximum. The rapid growth of $P$. kudriavzevii PKWF increased the consumption of oxygen, which provided an anaerobic environment for L. plantarum CWLP (Han et al., 2017). The viable count of L. plantarum CWLP reached its maximum value under the fermentation conditions of $37^{\circ} \mathrm{C}$, solid-liquid ratio $(1.2: 1 \mathrm{~g} / \mathrm{ml})$, and $72 \mathrm{~h}$. In 


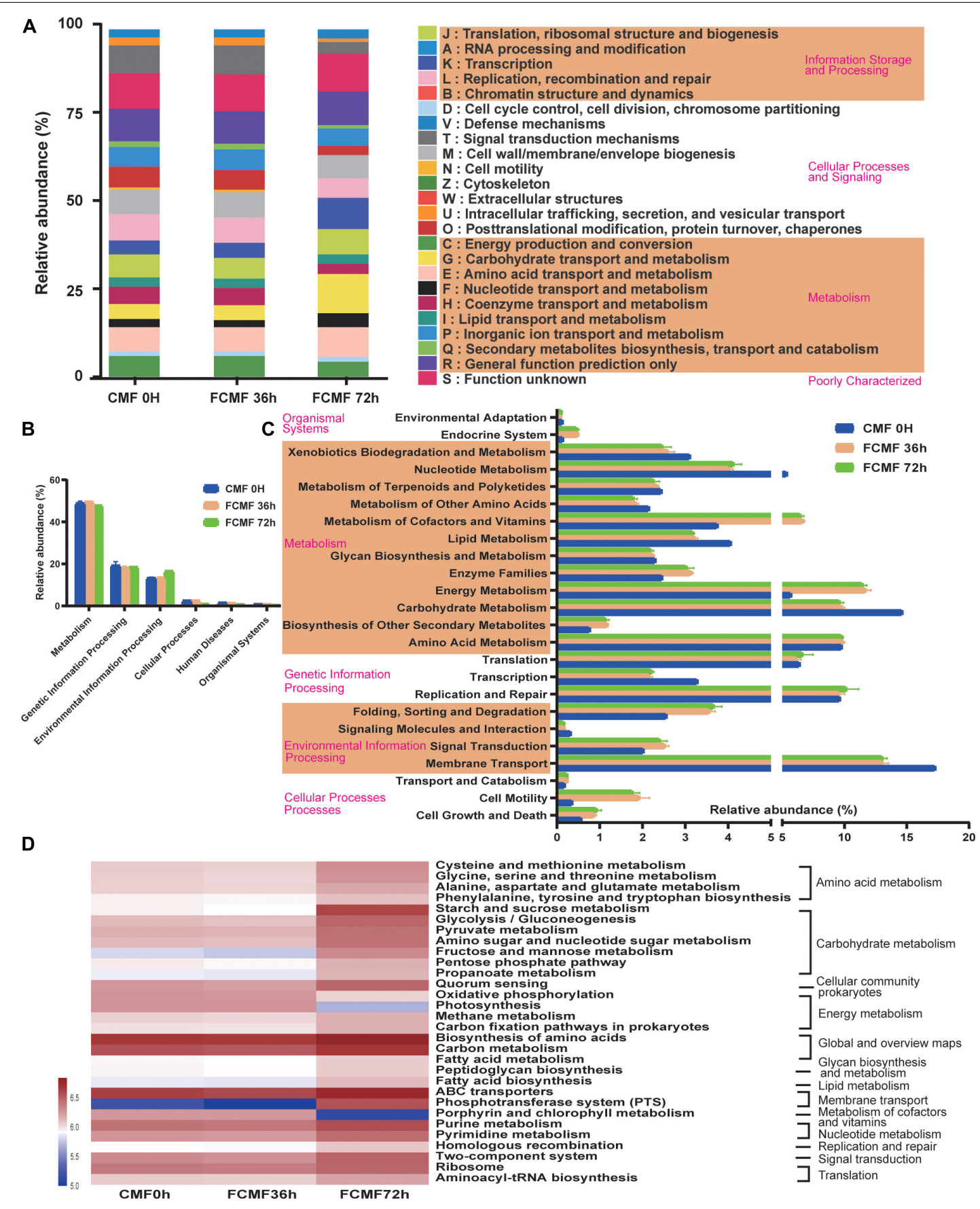

FIGURE 5 | Dynamics of bacterial functional profiles during CMF fermentation process analyzed by PICRUSt $(n=3)$. (A) Clusters of Orthologous Groups of protein (COG) function classification. (B) Level 1 metabolic pathways. (C) Level 2 Kyoto Encyclopedia of Genes and Genomes (KEGG) ortholog functional predictions. (D) Level 3 KEGG ortholog functional predictions of the relative abundances of the top 30 metabolic functions.

addition, neutral protease may have the optimal enzyme activity to degrade macromolecular proteins into TCA-SP at $37^{\circ} \mathrm{C}$. Accumulation of single-cell protein produced by microorganisms may lead to the increase in CP (Aggelopoulos et al., 2014; Mekoue Nguela et al., 2016), which reached its maximum under the fermentation conditions of $37^{\circ} \mathrm{C}$, solid-liquid ratio $(1.2: 1 \mathrm{~g} / \mathrm{ml})$, and $72 \mathrm{~h}$. In summary, we recommend the fermentation conditions of $37^{\circ} \mathrm{C}$, solid-liquid ratio $(1.2: 1 \mathrm{~g} / \mathrm{ml})$, and $72 \mathrm{~h}$ for SSF of CMF.

The content of CP, TCA-SP, and AA in CMF was significantly increased after the fermentation in our research. In addition to the accumulation of single-cell proteins produced by microorganisms, the loss of DM (mainly carbohydrates) in the fermentation substrate may be another reason for the relative 


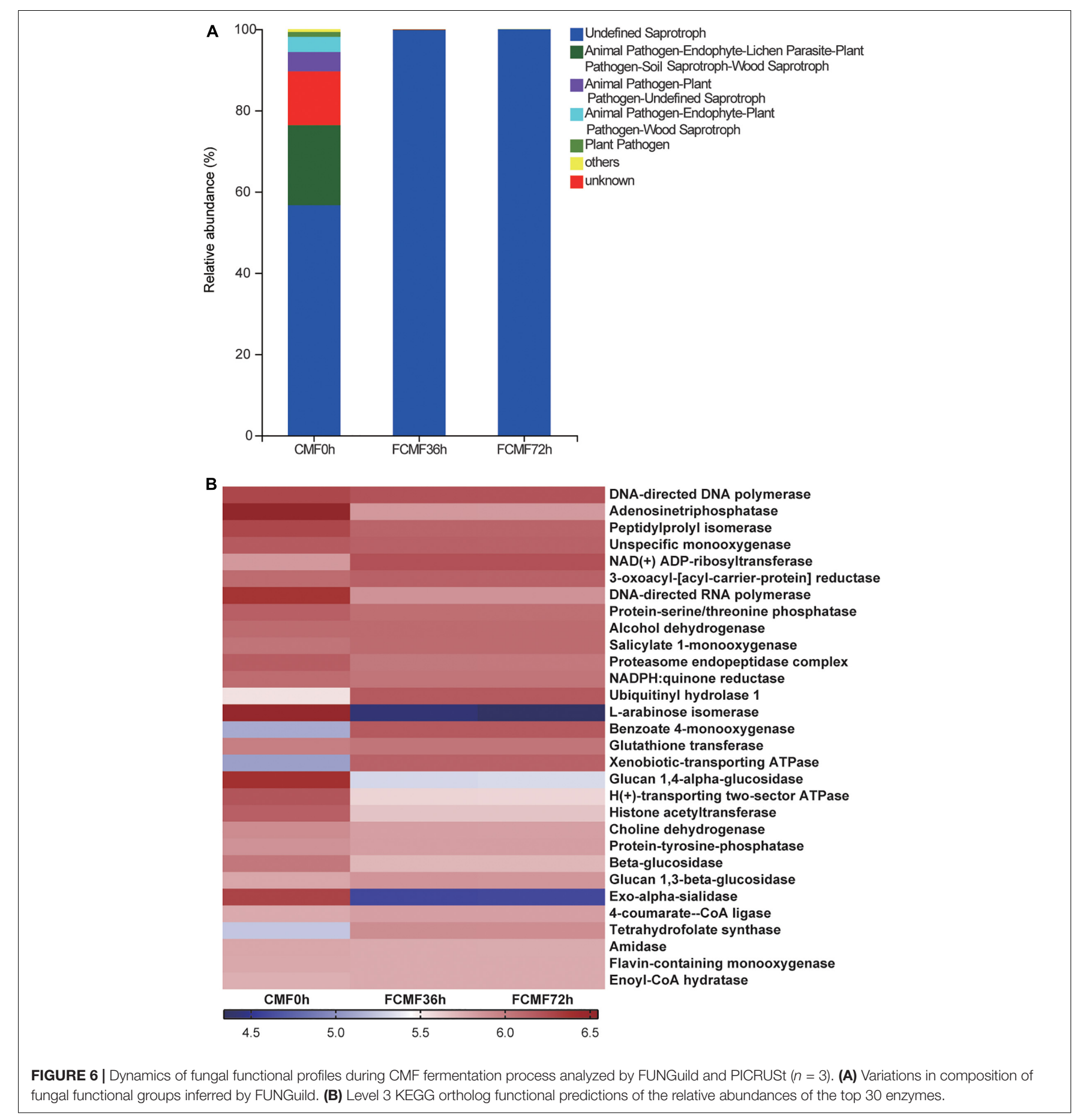

increase in the concentration of CP (Stokes and Gunness, 1946). TCA-SP consists of small peptides and free AA, most of which can be directly absorbed by the gastrointestinal tract (Gilbert et al., 2008). In addition, AA composition pattern changes during fermentation may be related to microbial protein synthesis and decomposition (Metges, 2000). Therefore, the increase in the content of TCA-SP and the change in AA composition can improve the nutritional value of CMF. Furthermore, the lignocellulosic components and amylose is poorly digested in the upper gut of monogastric animals (Regmi et al., 2011). CF, ADF, and amylose are effectively degraded after fermentation in this study, which might be due to the cellulase and amylase secreted by L. plantarum (Lee et al., 2019; Xu et al., 2020).

In contrast to CMF, FCMF exhibited small, cracked structures and large holes. The change in the surface structure of CMF after fermentation may be associated with extracellular enzymes (especially protease and carbohydrase) secreted during the process. The cracked and porous structure may provide increased 
access to enzymes for nutrient hydrolysis and may make the substrates considerably easier to utilize (Zheng et al., 2017), suggesting that FCMF had higher digestibility than CMF. Additionally, Tang et al. (2009) reported that smaller protein aggregates may result in a higher solubility. Zhao et al. (2015) found that soybean proteins with loose networks and diffuse structures have higher emulsification activity and solubility. Thus, the physicochemical properties of CMF may also have been affected by the changed microstructure in this study.

Digestibility is an essential method to evaluate the nutritional value of protein. The increase in CP and TCA-SP and the optimization of AA composition pattern in FCMF may be the main reasons for improving the in vitro digestibility of $\mathrm{CP}$ and AA. Some macromolecular proteins induce allergic reactions in humans and animals (Holzhauser et al., 2009; $\mathrm{Wu}$ et al., 2016). In the present study, CMF, fermented with P. kudriavzevii PKWF, L. plantarum CWLP, and neutral protease, contained less macromolecular proteins and more small peptides compared with CMF; the result was consistent with the previous report (Chi and Cho, 2016). In addition, the degradation of viscous-resistant starch and cellulose in FCMF leads to the exposure of internal proteins to the environment of pepsin and trypsin (Agama-Acevedo et al., 2005; Yang et al., 2010), which possibly contributes to the in vitro digestibility of $\mathrm{CP}$ and AA. Furthermore, the low $\mathrm{pH}$ value of FCMF is more effective to promote the function of pepsin (Mat et al., 2018).

High-throughput sequencing was first applied to analyze the changes in microbial community, including bacterial and fungal communities, structure, and metabolic functions during the fermentation process. The increase in OTU number during first-stage fermentation was because of the aerobic condition. In contrast, the second-stage fermentation process suggested that L. plantarum CWLP decreased OTU number, inhibited other bacteria and fungi, and became the dominant bacterium. The main phyla (Cyanobacteria, Proteobacteria, and Firmicutes) found in the present study were also obtained in some other studies related to SSF (Wang et al., 2020).

As fermentation progressed, unclassified_k_Fung and Basidiomycota became the predominant members of the community; Ascomycota were identified as the core genera during first stage of SSF. This type of fungi could consume oxygen in the first stage of fermentation, which may inhibit other pathogenic aerobic microorganisms. Meanwhile, Paenibacillus spp., Pantoea spp., and Lactobacillales spp. were predominant during the later $36 \mathrm{~h}$, and members of the heat-tolerant genus Paenibacillus spp. are effective at degrading proteins and cellulose during SSF due to their strong hydrolytic abilities (de Gannes et al., 2013). Lactobacillales spp. is a mesophilic genus whose members generate acid products (Yuan et al., 2018). Thus, these dominant genera indicated a selected community categorized by typical large-molecule catabolism characteristics, achieved by the addition of the two inoculated microbes. The evolution of bacterial and fungal structure during the process demonstrated that the artificially added inoculated microbes not only increased the number of added microbes but also boosted some other functional microbes that could develop a form of symbiosis with the inoculated microbes.

The results of KEGG levels 1 to 3 gene function analysis were generally consistent. As fermentation progressed, the abundances of both carbohydrate metabolism and AA metabolism genes gradually increased. Metabolism of cellulose and hemicellulose can produce many compounds that support bacterial growth (Toledo et al., 2017). AAs are also an energy and carbon source for bacteria (Sanchez et al., 2017). These results indicated that the degradation of large carbohydrate and proteins resulted in increased levels of saccharides and AAs, which could be utilized by the microbiota in FCMF. The gene abundances of membrane transporter, $\mathrm{ABC}$ transporters, and phosphotransferase system (PTS) increased during fermentation. These metabolic functions were associated with compound production and membrane transport, suggesting the mechanism of enzyme synthesis by, and activity of, the core bacteria in FCMF. In contrast, glycan biosynthesis and metabolism, and energy metabolism were inhibited by the core genera, indicating that these genes may be involved in native bacterial gene functions of CMF. Although the addition of L. plantarum inhibited the growth of other CMFnative microbes, it did not decrease the abundances of enzyme families. Additionally, the differences in the abundances of genes involved in global and overview maps (carbon metabolism) between the aerobic and anaerobic stages suggested the different metabolic roles of $P$. kudriavzevii and L. plantarum.

Various bacteria and fungi were correlated with different metabolic pathways, revealing that multiple metabolic pathways were active during the two stages of the SSF. Two inoculated microbes were enriched in environmental information processing and cellular processes throughout fermentation. These metabolic functions allowed the microbe to grow, proliferate, and respond to the environment (Kausar et al., 2011). The results demonstrated the superior adaptation of the inoculated microbes in response to fermentation.

\section{CONCLUSION}

In summary, two-stage SSF with $P$. kudriavzevii PKWF, L. plantarum CWLP, and neutral protease under the conditions of fermentation temperature of $37^{\circ} \mathrm{C}$, fermentation time of $72 \mathrm{~h}$, and solid-liquid ratio of $1.2: 1 \mathrm{~g} / \mathrm{ml}$ effectively improved protein digestibility in CMF through degrading macromolecular protein into TCA-SP, improving AA composition patterns and degrading lignocellulose to expose internal nutrients. Therefore, this study provides a novel method for improving the nutritional quality of CMF and provides a basis for demonstrating that the inoculated microbes dynamically change the physicochemical features, microbiota, and metabolic functions during the twostage SSF, which could serve as a valuable resource for industrial feed-based practices and metabolomic research on SSF systems; besides, this study also provides a strategy for the utilization of CBs as feed materials. Further studies should focus on the use of additional enzymes and inoculation with other bacteria during fermentation to further reduce the ANF content of FCMF and produce various types of organic acids. 


\section{DATA AVAILABILITY STATEMENT}

The original contributions presented in the study are included in the article/Supplementary Material, further inquiries can be directed to the corresponding authors.

\section{AUTHOR CONTRIBUTIONS}

WS: investigation, data curation, and writing-original draft. ZJ: investigation, software, and writing original draft. LH: visualization. WL: project administration. TG: resources. YZ: formal analysis. SD and CW: software and validation. ZL and MJ: conceptualization, supervision, and writing review and editing. YW: supervision, funding acquisition, methodology, software, and writing review and editing. All authors contributed to the article and approved the submitted version.

\section{FUNDING}

The design of the study and collection, analysis, and interpretation of data were supported by the China Agriculture Research System of MOF and MARA (CARS-35), the Key Agriculture Program of Zhejiang Major Science and

\section{REFERENCES}

Agama-Acevedo, E., Rendón-Villalobos, R., Tovar, J., Trejo-Estrada, S. R., and Bello-Pérez, L. A. (2005). Effect of storage time on in vitro digestion rate and resistant starch content of tortillas elaborated from commercial corn masas. Arch. Latinoam. Nutr. 55, 86-92.

Aggelopoulos, T., Katsieris, K., Bekatorou, A., Pandey, A., Banat, I. M., and Koutinas, A. A. (2014). Solid state fermentation of food waste mixtures for single cell protein, aroma volatiles and fat production. Food Chem. 145, 710716. doi: 10.1016/j.foodchem.2013.07.105

Anderson, P. V., Kerr, B. J., Weber, T. E., Ziemer, C. J., and Shurson, G. C. (2012). Determination and prediction of digestible and metabolizable energy from chemical analysis of corn coproducts fed to finishing pigs. J. Anim. Sci. 90, 1242-1254. doi: 10.2527/jas.2010-3605

Arevalo-Villena, M., Briones-Perez, A., Corbo, M. R., Sinigaglia, M., and Bevilacqua, A. (2017). Biotechnological application of yeasts in food science: starter cultures, probiotics and enzyme production. J. Appl. Microbiol. 123, 1360-1372. doi: 10.1111/jam.13548

Bedrosian, M. C. D., and Kung, L. M. (2019). The effect of various doses of an exogenous acid protease on the fermentation and nutritive value of corn silage. J. Dairy Sci. 102, 10925-10933. doi: 10.3168/jds.2019-16436

Chen, F. D., and Stappenbeck, T. S. (2019). Microbiome control of innate reactivity. Curr. Opin. Immunol. 56, 107-113. doi: 10.1016/j.coi.2018.12.003

Chi, C. H., and Cho, S. J. (2016). Improvement of bioactivity of soybean meal by solid-state fermentation with Bacillus amyloliquefaciens versus Lactobacillus spp. and Saccharomyces cerevisiae. LWT Food Sci. Technol. 68, 619-625. doi: 10.1016/j.lwt.2015.12.002

de Gannes, V., Eudoxie, G., and Hickey, W. J. (2013). Prokaryotic successions and diversity in composts as revealed by 454-pyrosequencing. Bioresour. Technol. 133, 573-580. doi: 10.1016/j.biortech.2013.01.138

Decimo, M., Quattrini, M., Ricci, G., Fortina, M. G., Brasca, M., Silvetti, T., et al. (2017). Evaluation of microbial consortia and chemical changes in spontaneous maize bran fermentation. AMB Express 7:205. doi: 10.1186/s13568-017-0506-y

Deng, N., Du, H., and Xu, Y. (2020). Cooperative response of Pichia kudriavzevii and Saccharomyces cerevisiae to lactic acid stress in Baijiu fermentation. J. Agric. Food Chem. 68, 4903-4911. doi: 10.1021/acs.jafc.9b08052
Technology Projects (2019C02051), the Major Scientific and Technological Innovation Projects of Shandong Province of China (2019JZZY020602), and the 2020 Talent Cultivation Project by Zhejiang Association for Science and Technology (CTZB-2020080127).

\section{ACKNOWLEDGMENTS}

The authors thank the specialized research fund from the China Agriculture Research System of MOF and MARA (CARS35), the Key Agriculture Program of Zhejiang Major Science and Technology Projects (2019C02051), the Major Scientific and Technological Innovation Projects of Shandong Province of China (2019JZZY020602), and the 2020 Talent Cultivation Project by Zhejiang Association for Science and Technology (CTZB-2020080127).

\section{SUPPLEMENTARY MATERIAL}

The Supplementary Material for this article can be found online at: https://www.frontiersin.org/articles/10.3389/fmicb. 2021.688839/full\#supplementary-material

Faurobert, M. (1997). Application of two-dimensional gel electrophoresis to Prunus armeniaca leaf and bark tissues. Electrophoresis 18, 170-173. doi: 10. 1002/elps.1150180130

Franklin, M. A., Mathew, A. G., Vickers, J. R., and Clift, R. A. (2002). Characterization of microbial populations and volatile fatty acid concentrations in the jejunum, ileum, and cecum of pigs weaned at 17 vs 24 days of age. J. Anim. Sci. 80, 2904-2910. doi: 10.2527/2002.80112904x

Fukuda, S., Toh, H., Hase, K., Oshima, K., Nakanishi, Y., Yoshimura, K., et al. (2011). Bifidobacteria can protect from enteropathogenic infection through production of acetate. Nature 469, 543-547. doi: 10.1038/nature09646

Gilbert, E. R., Wong, E. A., and Webb, K. E. (2008). Board-invited review: peptide absorption and utilization: implications for animal nutrition and health. J. Anim. Sci. 86, 2135-2155. doi: 10.2527/jas.2007-0826

Han, G., Webb, M. R., Richter, C., Parsons, J., and Waterhouse, A. L. (2017). Yeast alter micro-oxygenation of wine: oxygen consumption and aldehyde production. J. Sci. Food Agric. 97, 3847-3854. doi: 10.1002/jsfa.8252

Hezarjaribi, M., Ardestani, F., and Ghorbani, H. R. (2016). Single cell protein production by Saccharomyces cerevisiae using an optimized culture medium composition in a batch submerged bioprocess. Appl. Biochem. Biotechnol. 179, 1336-1345. doi: 10.1007/s12010-016-2069-9

Holzhauser, T., Wackermann, O., Ballmer-Weber, B. K., Bindslev-Jensen, C., Scibilia, J., Perono-Garoffo, L., et al. (2009). Soybean (Glycine max) allergy in Europe: Gly m 5 (beta-conglycinin) and Gly $\mathrm{m} 6$ (glycinin) are potential diagnostic markers for severe allergic reactions to soy. J. Allergy Clin. Immunol. 123, 452-458. doi: 10.1016/j.jaci.2008.09.034

Kausar, H., Sariah, M., Saud, H. M., Alam, M. Z., and Ismail, M. R. (2011). Isolation and screening of potential actinobacteria for rapid composting of rice straw. Biodegradation 22, 367-375. doi: 10.1007/s10532-010-9407-3

Lee, F. H., Wan, S. Y., Foo, H. L., Loh, T. C., Mohamad, R., Abdul Rahim, R., et al. (2019). Comparative study of extracellular proteolytic, cellulolytic, and hemicellulolytic enzyme activities and biotransformation of palm kernel cake biomass by lactic acid bacteria isolated from Malaysian foods. Int. J. Mol. Sci. 20:4979. doi: 10.3390/ijms20204979

Li, J., Zhou, R. I., Ren, Z. q, Fan, Y-w, Hu, S-b, Zhou, C-f, et al. (2019). Improvement of protein quality and degradation of allergen in soybean meal fermented by Neurospora crassa. LWT 101, 220-228. doi: 10.1016/j.lwt.2018.10.089 
Li, Y., Li, Z., Liu, H., Noblet, J., Liu, L., Li, D., et al. (2018). Net energy content of rice bran, corn germ meal, corn gluten feed, peanut meal, and sunflower meal in growing pigs. Asian Aust. J. Anim. Sci. 31, 1481-1490. doi: 10.5713/ajas.17.0829

Mat, D. J. L., Cattenoz, T., Souchon, I., Michon, C., and Le Feunteun, F. (2018). Monitoring protein hydrolysis by pepsin using $\mathrm{pH}$-stat: in vitro gastric digestions in static and dynamic pH conditions. Food Chem. 239, 268-275. doi: 10.1016/j.foodchem.2017.06.115

Meinlschmidt, P., Sussmann, D., Schweiggert-Weisz, U., and Eisner, P. (2016). Enzymatic treatment of soy protein isolates: effects on the potential allergenicity, technofunctionality, and sensory properties. Food Sci. Nutr. 4, 11-23. doi: $10.1002 /$ fsn 3.253

Mekoue Nguela, J., Poncet-Legrand, C., Sieczkowski, N., and Vernhet, A. (2016). Interactions of grape tannins and wine polyphenols with a yeast protein extract, mannoproteins and beta-glucan. Food Chem. 210, 671-682. doi: 10.1016/j. foodchem.2016.04.050

Metges, C. C. (2000). Contribution of microbial amino acids to amino acid homeostasis of the host. J. Nutr. 130, 1857s-1864s. doi: 10.1093/jn/130.7.1857S

Missotten, J. A. M., Michiels, J., Degroote, J., and De Smet, S. (2015). Fermented liquid feed for pigs: an ancient technique for the future. J. Anim. Sci. Biotechnol. 6:4. doi: 10.1186/2049-1891-6-4

Ni, K. K., Wang, F., Zhu, B., Yang, J., Zhou, G., Pan, Y., et al. (2017). Effects of lactic acid bacteria and molasses additives on the microbial community and fermentation quality of soybean silage. Bioresour. Technol. 238, 706-715. doi: 10.1016/j.biortech.2017.04.055

Nielsen, H. C., Wall, J. S., and Inglett, G. E. (1979). Flour containing protein and fiber made from wet-mill corn germ, with potential food use. Cereal Chem. 56, 144-146.

Ovissipour, M., Abedian, A., Motamedzadegan, A., Rasco, B., Safari, R., and Shahiri, H. (2009). The effect of enzymatic hydrolysis time and temperature on the properties of protein hydrolysates from Persian sturgeon (Acipenser persicus) viscera. Food Chem. 115, 238-242. doi: 10.1016/j.foodchem.2008.12.013

Regmi, P. R., van Kempen, T. A., Matte, J. J., and Zijlstra, R. T. (2011). Starch with high amylose and low in vitro digestibility increases short-chain fatty acid absorption, reduces peak insulin secretion, and modulates incretin secretion in pigs. J. Nutr. 141, 398-405. doi: 10.3945/jn.110.132449

Sakamoto, K., Asano, T., Furuya, A., and Takahashi, S. (2008). Estimation of in vivo digestibility with the laying hen by an in vitro method using the intestinal fluid of the pig. Br. J. Nutr. 43, 389-391. doi: 10.1079/BJN19800103

Sanchez, O. J., Ospina, D. A., and Montoya, S. (2017). Compost supplementation with nutrients and microorganisms in composting process. Waste Manag. 69, 136-153. doi: 10.1016/j.wasman.2017.08.012

Shi, C. Y., Zhang, Y., Lu, Z., and Wang, Y. (2017). Solid-state fermentation of cornsoybean meal mixed feed with Bacillus subtilis and Enterococcus faecium for degrading antinutritional factors and enhancing nutritional value. J. Anim. Sci. Biotechnol. 8:50. doi: 10.1186/s40104-017-0184-2

Soares, V. F., Castilho, L. R., Bon, E. P. S., and Freire, D. M. G. (2005). High-yield Bacillus subtilis protease production by solid-state fermentation. Appl. Biochem. Biotechnol. 121, 311-319. doi: 10.1007/978-1-59259-991-2_27

Stein, H. H., Lagos, L. V., and Casas, G. A. (2016). Nutritional value of feed ingredients of plant origin fed to pigs. Anim. Feed Sci. Technol. 218, 33-69. doi: 10.1016/j.anifeedsci.2016.05.003

Stokes, J. L., and Gunness, M. (1946). The amino acid composition of microorganisms. J. Bacteriol. 51, 9-10. doi: 10.1128/jb.52.2.195-207.1946

Tang, C.-H., Wang, X.-Y., Yang, X.-Q., and Li, L. (2009). Formation of soluble aggregates from insoluble commercial soy protein isolate by means of ultrasonic treatment and their gelling properties. J. Food Eng. 92, 432-437. doi: 10.1016/j. jfoodeng.2008.12.017

Toledo, M., Gutiérrez, M. C., Siles, J. A., García-Olmo, J., and Martín, M. A. (2017). Chemometric analysis and NIR spectroscopy to evaluate odorous impact during the composting of different raw materials. J. Clean. Prod. 167, 154-162. doi: 10.1016/j.jclepro.2017.08.163

Wang, C., Shi, C., Su, W., Jin, M., Xu, B., Hao, L., et al. (2020). Dynamics of the physicochemical characteristics, microbiota, and metabolic functions of soybean meal and corn mixed substrates during two-stage solid-state fermentation. mSystems 5:e0501-19. doi: 10.1128/mSystems.00501-19
Wang, C., Shi, C., Zhang, Y., Song, D., Lu, Z., and Wang, Y. (2018a). Microbiota in fermented feed and swine gut. Appl. Microbiol. Biotechnol. 102, 2941-2948. doi: 10.1007/s00253-018-8829-4

Wang, C., Su, W., Zhang, Y., Hao, L., Wang, F., Lu, Z., et al. (2018b). Solid-state fermentation of distilled dried grain with solubles with probiotics for degrading lignocellulose and upgrading nutrient utilization. $A M B$ Express 8:188. doi: 10.1186/s13568-018-0715-Z

Wong, H. C., and Chen, Y. L. (1988). Effects of lactic-acid bacteria and organicacids on growth and germination of Bacillus cereus. Appl. Environ. Microbiol. 54, 2179-2184. doi: 10.1128/aem.54.9.2179-2184.1988

Wu, J. J., Cao, C. M., Meng, T. T., Zhang, Y., Xu, S. L., Feng, S. B., et al. (2016). Induction of immune responses and allergic reactions in piglets by injecting glycinin. Ital. J. Anim. Sci. 15, 166-173. doi: 10.1080/1828051X.2016.114 4488

Xu, Y., Ding, J., Gong, S., Li, M., Yang, T., and Zhang, J. (2020). Physicochemical properties of potato starch fermented by amylolytic Lactobacillus plantarum. Int. J. Biol. Macromol. 158, 656-661. doi: 10.1016/j.ijbiomac.2020. 04.245

Yang, Y., Kiarie, E., Slominski, B. A., Brûlé-Babel, A., and Nyachoti, C. M. (2010). Amino acid and fiber digestibility, intestinal bacterial profile, and enzyme activity in growing pigs fed dried distillers grains with solubles-based diets. J. Anim. Sci. 88, 3304-3312. doi: 10.2527/jas.20092318

Yuan, S. F., Hsu, T. C., Wang, C. A., Jang, M. F., Kuo, Y. C., Alper, H. S., et al. (2018). Production of optically pure L(+)-lactic acid from waste plywood chips using an isolated thermotolerant Enterococcus faecalis SI at a pilot scale. J. Ind. Microbiol. Biotechnol. 45, 961-970. doi: 10.1007/s10295-0182078-5

Zhang, Y., Shi, C., Wang, C., Lu, Z., Wang, F., Feng, J., et al. (2018). Effect of soybean meal fermented with Bacillus subtilis BS12 on growth performance and small intestinal immune status of piglets. Food Agric. Immunol. 29, 133-146. doi: 10.1080/09540105.2017.1360258

Zhao, X., Zhu, H., Zhang, B., Chen, J., Ao, Q., and Wang, X. (2015). XRD, SEM, and XPS analysis of soybean protein powders obtained through extraction involving reverse micelles. J. Am. Oil Chem. Soc. 92, 975-983. doi: 10.1007/s11746-0152657-9

Zheng, L., Li, D., Li, Z. L., Kang, L. N., Jiang, Y. Y., Liu, X. Y., et al. (2017). Effects of Bacillus fermentation on the protein microstructure and anti-nutritional factors of soybean meal. Lett. Appl. Microbiol. 65, 520-526. doi: 10.1111/lam. 12806

Zhu, Y. H., Li, X. Q., Zhang, W., Zhou, D., Liu, H. Y., and Wang, J. F. (2014). Dose-dependent effects of Lactobacillus rhamnosus on serum interleukin-17 production and intestinal T-cell responses in pigs challenged with Escherichia coli. Appl. Environ. Microbiol. 80, 1787-1798. doi: 10.1128/AEM.03668-13

Zong, X., Fu, J., Xu, B., Wang, Y., and Jin, M. (2020). Interplay between gut microbiota and antimicrobial peptides. Anim. Nutr. 6, 389-396. doi: 10.1016/ j.aninu.2020.09.002

Conflict of Interest: The authors declare that the research was conducted in the absence of any commercial or financial relationships that could be construed as a potential conflict of interest.

Publisher's Note: All claims expressed in this article are solely those of the authors and do not necessarily represent those of their affiliated organizations, or those of the publisher, the editors and the reviewers. Any product that may be evaluated in this article, or claim that may be made by its manufacturer, is not guaranteed or endorsed by the publisher.

Copyright (C) 2021 Su, Jiang, Hao, Li, Gong, Zhang, Du, Wang, Lu, Jin and Wang. This is an open-access article distributed under the terms of the Creative Commons Attribution License (CC BY). The use, distribution or reproduction in other forums is permitted, provided the original author(s) and the copyright owner(s) are credited and that the original publication in this journal is cited, in accordance with accepted academic practice. No use, distribution or reproduction is permitted which does not comply with these terms. 